\title{
Hidrometalurjik Yöntemlerle Nadir Toprak Elementlerinin Kazanılması
}

\author{
Mehmet Kayra Tanaydın ${ }^{1,2}$ \\ ${ }^{I}$ Munzur Üniversitesi, Tunceli Meslek Yüksekokulu, Kimya ve Kimyasal Prosesler Bölümü, Tunceli, Türkiye \\ ${ }^{2}$ Munzur Üniversitesi, Nadir Toprak Elementleri Araştırma ve Uygulama Merkezi, Tunceli, Türkiye \\ mtanaydin@munzur.edu.triD \\ Makale gönderme tarihi: 03.04.2021, Makale kabul tarihi: 24.06.2021
}

\begin{abstract}
$\ddot{O} \mathbf{z}$
Dünya'da nadir toprak elementlerine olan talep hızla artmakta, buna karşın Çin hükümetinin dayattığı ihracat kotaları ve yasadışı madencilik operasyonları nedeniyle bu elementlerin arz miktarları azalmaktadır. Birçok ülke önlemler alarak gelecekteki ihtiyaçlarını karşılamak için nadir toprak elementlerini birincil ve ikincil kaynaklardan kazanmaya yönelik çalışmalarını hızlandırmıştır. Nadir toprak elementleri, hem günlük yaşantımızda kullandığımız yüksek teknoloji ürünlerinin tasarlanması ve geliştirilmesi hem de modern endüstrinin ilerlemesi için gerekli olan en önemli bileşenlerdir. Hayatımızın vazgeçilmez malzemeleri haline gelen bu elementler doğada genellikle saf halde değil, cevherlerde kompleks yapıda bulunurlar. Nadir toprak elementleri 250'ye yakın bilenen minerale sahiptir ancak bunlardan bastnazit, monazit ve ksenotim gibi cevherler ticari olarak işletilmektedir. Bastnazit, monazit ve ksenotim konsantreleri elde etmek için genellikle flotasyon, gravite, elektrostatik veya manyetik ayırma işlemleri ile fiziksel olarak zenginleştirilirler. Uygulanabilir ve çevre dostu prosesler geliştirmek için, nadir toprak elementlerinin liç çözeltilerinden (klorür, nitrat, sülfat, tiyosiyanat, vb. ortamlarda) ekstraksiyonu, çözelti ortamına bağlı olarak farklı katyonik, anyonik ve nötr ekstraktantların kullanılmasına yönelik çalışmalar yürütülmektedir. Nadir toprak elementlerinin ticari ekstraksiyonu $\mathrm{D}_{2}$ EHPA, Cyanex 272, PC-88A, Versatic 10, TBP, Aliquat 336 vb. farklı ekstraktantlar kullanılarak gerçekleştirilmektedir. Bu makalede, nadir toprak elementlerinin birincil kaynaklardan kazanılması için kullanılan hidrometalurjik yöntemler incelenmiştir. Bu yöntemler, asitler ve alkaliler ile liç ve ardından solvent ekstraksiyonu, iyon değişimi veya çöktürme ve indirgenme gibi proseslerden oluşan hidrometalurjik yöntemlerdir. Hidrometalurjik proseslerin uygulanmasıyla çeşitli şartlar altında nadir toprak elementlerinin kazanımı için yararlı olabilecek prosesler değerlendirilmiştir.
\end{abstract}

Anahtar Kelimeler: Hidrometalurji, liç, solvent ekstraksiyonu, nadir toprak elementleri

\section{Recovery of Rare Earth Elements by Hydrometallurgical Methods}

\begin{abstract}
The demand for rare earth elements in the world is increasing rapidly, but the supply amounts of these elements are decreasing due to export quotas imposed by the Chinese government and illegal mining operations. Many countries have accelerated their efforts to obtain rare earth elements from primary and secondary sources in order to meet their future needs by taking measures. Rare earth elements are the most important components necessary both for the design and development of high-tech products that we use in our daily lives and for the advancement of modern industry. These elements, which have become indispensable materials of our lives, are generally not found in pure form in nature, but in complex structures in ores. Rare earth elements have close to 250 known minerals, but ores such as bastnasite, monazite and xenotime are commercially exploited. It is usually physically enriched by flotation, gravity, electrostatic or magnetic separation processes to obtain bastnasite, monazite and xenotime concentrates. In order to develop viable and environmentally friendly processes, studies are carried out for the extraction of rare earth elements from leaching solutions (chloride, nitrate, sulfate, thiocyanate, etc.) and the use of different cationic, anionic and neutral extractants depending on the solution medium. Commercial extraction of rare earth elements D2EHPA, Cyanex 272, PC-88A, Versatic 10, TBP, Aliquat 336 etc. carried out using different extractants. In this work, hydrometallurgical methods used for the recovery of rare earth elements from primary sources are examined. These methods are hydrometallurgical methods consisting of leaching with acids and alkalis followed by processes such as solvent extraction, ion exchange or precipitation and reduction. With the application of hydrometallurgical processes, processes that may be beneficial for the recovery of rare earth elements under various conditions have been evaluated.
\end{abstract}


Keywords: Hydrometallurgy, leaching, solvent extraction, rare earth elements

\section{GİRIS}

Özgün fiziksel, kimyasal özellikleri ve uygulamaları nedeniyle son y1llarda nadir toprak elementlerine (NTE'lerine) olan talepte artış gözlenmiştir. Günümüzde Çin toplam NTE'lerinin \%80'ninden fazlasını üreten dünyanın en büyük tedarikçisi haline gelmiştir (Mancheri ve ark., 2019). NTE'leri ilave edilen ürünlerin kararlı, yüksek sıcaklığa, korozyona ve aşınmaya karşı dirençli olmalarını sağlamaktadır (Voncken, 2016b). NTE'leri elektrokimyasal, optik, manyetik, nükleer, alaşım, lüminesans, katalitik vs. proseslerinde kullanılmalarından dolayı giderek daha önemli kaynaklar haline gelmektedir. Elektrikli araçlar, yeşil enerji üretimi, elektronik cihazlar ve yüksek performanslı uçaklar gibi birçok son teknoloji ürünlerin bileşenlerinde veya ekipmanlarda kullanımlarından dolayı NTE'leri son derece önemlidir (Jowitt ve ark., 2018).

NTE'lerinin yerine konabilecek ikame malzemeler henüz bulunmamaktadır. Kullanıldığı ürünlerin ana hammaddesi olmayıp genellikle belirli oranlarda katk 1 maddesi olarak ilave edilmekte ve bu malzemelerin üstün özellikler kazanmasını sağlamaktadır (Lucas ve ark., 2014; Voncken, 2016b). NTE'leri benzer kimyasal özelliklerinden dolayı ayırma ve saflaştırma zorluklarına sahiptir. NTE'lerin sahip olduğu bu benzer özelliklerinden dolayı; yumuşak, dövülebilir, sünek, yoğun ve oda şartlarında havadan aynı şekilde etkilenmezler. Bazıları çok hızlı aşınırken (Eu) bazıları yıllarca bozulmadan kalabilir (La) (Voncken, 2016a).

Periyodik tabloda NTE'leri kimyasal açıdan benzer özellikte olan ve lantanitler olarak da adlandirılan, atom numarasi 57 olan lantanumdan (La), 71 olan lutesyuma (Lu) kadar olan elementler ayrı bir grubun birleşiminden oluşmaktadır. Periyodik tabloda 21 atom numaralı skandiyum ve 39 atom numaralı itriyum da benzer kimyasal özellik göstermelerinden dolayı lantanitler arasında yer almaktadır. Prometyum (atom numarasi: 61) radyoaktif bir element olup, uygulamalar için yapay olarak elde edilmektedir. NTE'leri, atom numaraları
57-64 atom numaraları aralığındaki elementler hafif NTE'leri ( $\mathrm{La}, \mathrm{Ce}, \mathrm{Pr}, \mathrm{Nd}, \mathrm{Pm}, \mathrm{Sm}, \mathrm{Eu}$ ) ve atom numarası 65-71 aralığındaki elementler ağır nadir toprak elementleri (Gd, Tb, Dy, Ho, Er, Tm, Yb, Lu, Y) alt gruplarına ayrılmaktadır (Kogel ve ark., 2006).

Avrupa komisyonunun 2017 y1llında hazırladığ raporda nadir toprak elementlerini kritik malzemeler grubuna dahil etmiştir. Bu raporda hafif NTE'lerini de ağır NTE'leri kadar kritik malzemeler seviyesine yükseltmiştir (European Commission, 2017). Yerkabuğunda NTE'lerinin ortalama içeriği $\% 0.015$ 'e yakın olduğu ve NTE'i içeren yaklaşık 250'den fazla mineral bilinmektedir (Hu ve ark., 2004). Jeolojik araştırmalara göre, monazit [(Ce, $\left.\left.\mathrm{La}) \mathrm{PO}_{4}\right)\right]$, bastnazit $\left[(\mathrm{Ce}, \mathrm{La})\left(\mathrm{CO}_{3}\right) \mathrm{F}\right]$, ve ksenotim, NTE'leri ile zenginleştirilmiş ve ticarileştirme için uygun olan üç ana mineraldir (Arslan Topal ve Elitok, 2018; Bakıcı Tanaydın ve ark., 2020; Golev ve ark., 2014; Kastori ve ark., 2010).

Dünyadaki NTE'i rezervlerinin neredeyse \%95'ine katkıda bulunan ticari NTE'i mineral kaynakları bastnazit (\%53-79 NTEO'leri), monazit (\%35-71 NTEO'leri), ksenotim (\%43-65 NTEO’leri) olarak bilinmektedir (Migaszewski ve Gałuszka, 2015). Dünyada yaklaşı 130 milyon ton nadir toprak element rezervi bulunmaktadır. Bu rezervin \%33'ü Çin, \%17'si Brezilya, \%17'si Vietnam, \%13'ü Rusya ve \%20'lik kısmı da diğer ülkelerde bulunmaktadır (Balaram, 2019).

Dünya nadir toprak mineralleri üretiminin (oksit olarak) yaklaşık \%80'i bastnazit, \%4'ü monazit ve ksenotim, geriye kalanı da diğer kaynaklardan üretilmektedir (Kanazawa ve Kamitani, 2006). Cevherlerinden NTE'lerini kazanmak için kullanılan en önemli yöntem hidrometalurji olarak bilinmektedir. Hidrometalurjik prosesler genellikle fiziksel zenginleştirme (manyetik, yerçekimi ile, elektrostatik ve flotasyon prosesleri), kavurma, liç (kimyasal prosesler), ayırma (solvent ekstraksiyonu, iyon değişim, çöktürme vs.), saflaştırma ve kazanma basamaklarını içermektedir. Şekil 1'de görüldüğg̈ gibi NTE 


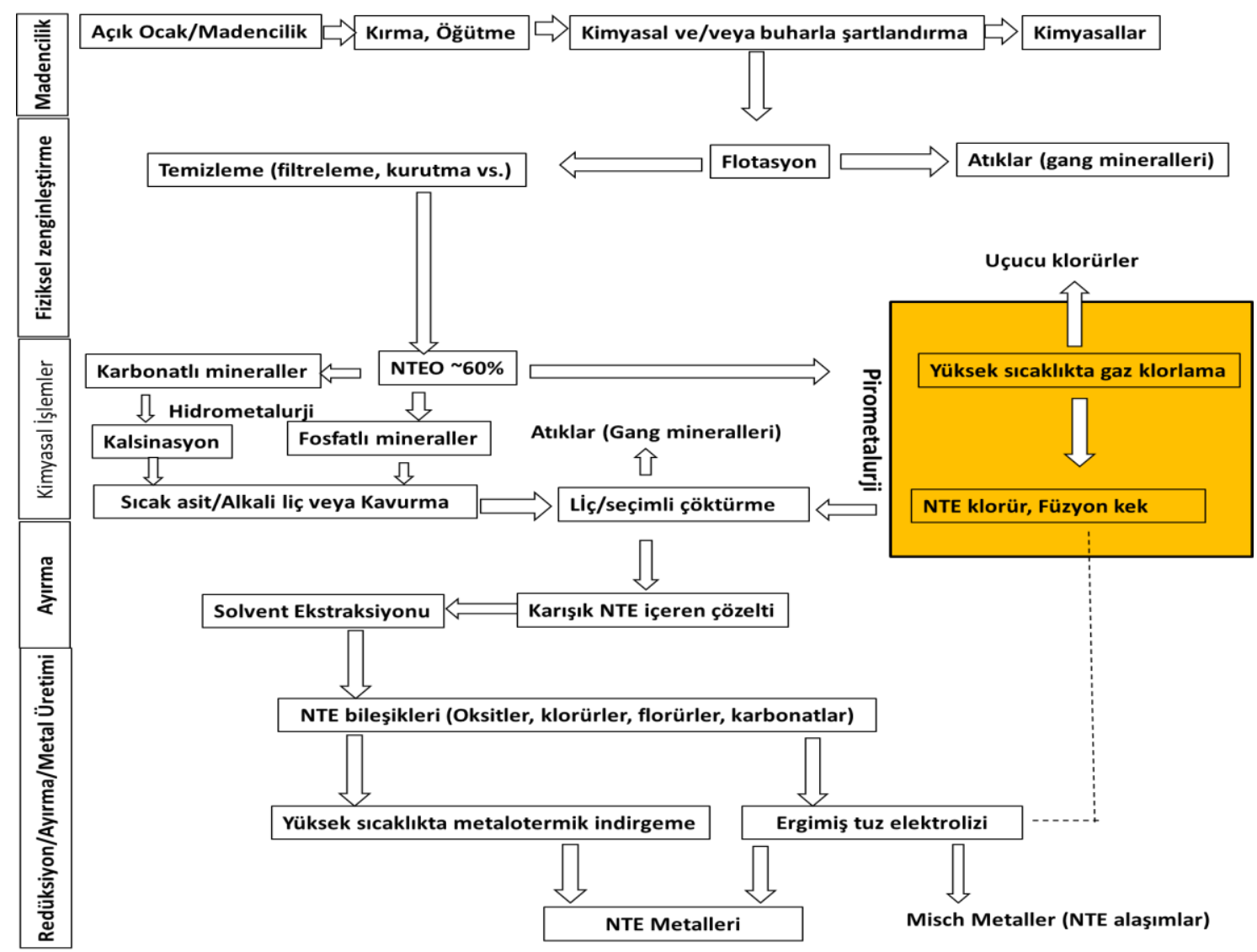

Şekil 1. Yaygın bir şekilde kullanılan nadir toprak element metalurji prosesi (NTE: Nadir Toprak Elementleri, NTEO: Nadir Toprak Element Oksitleri) (Ismail ve ark., 2019)

metalurjisi, madencilik, fiziksel zenginleştirme, kimyasal işlemler, ayırma ve arıtma işlemleri gibi sürekli birbirini takip eden proses hattı üzerinden yürümektedir (Ismail ve ark., 2019).

\section{Liç İşlemi}

NTE'i içeren konsantrelerin kimyasal işlemden geçirilmesi, safsızlıkları giderdiği gibi NTEO konsantresini de yaklaşık \%90'a çıkarabilmektedir. Fiziksel olarak zenginleştirilmiş konsantreler, NTE değerlerini kazanmak için genellikle 1sıl işlem ve ardından liç, çöktürme, solvent ekstraksiyonu (SX) ve iyon değişiminden oluşan pirometalurjik ve/veya hidrometalurjik işlemlerle gerçekleştirilmektedir. Minerallerin NTE içeren kısımlarını çözmek için fiziksel olarak zenginleştirilmiş konsantrenin uygun asidik veya alkali çözeltilerle doğrudan veya 1 s1l işlemden sonra liç edilmesi gerekmektedir. Liç çözeltileri, farklı $\mathrm{pH}$ koşulları altında oluşan nadir toprak komplekslerini belirlemede kullanılmaktadır. Bayan Obo prosesinde NTE'lerinin kazanılması için kullanılan ana işlem, konsantre cevherin \%98'lik $\mathrm{H}_{2} \mathrm{SO}_{4}$ çözeltisi ile birkaç saat yaklaşık $500^{\circ} \mathrm{C}$ ye 1sitılarak bastnazitin sülfürik asitle kavrulmasıdır. $\mathrm{Bu}$ işlem, NTE'leri sülfatlarına dönüştüren florokarbonat matrisini ayrıştırır ve son derece tehlikeli olan ve bu nedenle dikkatle işlenmesi gereken $\mathrm{CO}_{2}$ ve $\mathrm{HF}$ gazlarını serbest birakmaktadır (Jha ve ark., 2016). Şekil 2'de Çin'deki Baotou NTE konsantreleri için uygulanan liç işlemine ait bir akış şeması verilmiştir.

Bastnazite benzer şekilde, monazit, içinde bulunan metalleri liç etmek için uygun koşullar gerektirmektedir. Yüksek toryum içeriği, monazit prosesinin ana dezavantajıdır. Liç işleminden önce konsantre cevherin öğütülmesi gerekmektedir. Monaziti ayrıştırmak için, $150^{\circ} \mathrm{C}$ 'de sülfürik asit veya sodyum hidroksit ile liç işleminin uygulanması gerekebilir. İşlem sonrası NTE'leri ve toryum hidroksit içeren kek konsantresi, sıcak bir asidik çözelti ile liç edilerek, daha sonraki safhalarda NTE'lerini ayırmak için uygun hale getirilmektedir. Alkali liç işleminin bir yan ürünü olan trisodyum 
fosfat geri kazanılırak satılabilir bir ürün haline getirilmektedir. Bununla birlikte, toryum eşzamanlı olarak liç edilebilir, ancak bu safhada radyoaktif ürünlerde oluşabileceği için proses tasarımı sırasında gerekli önlemlerin alınması gerekmektedir.

Monazit cevherini işlemek için kullanılan diğer bir yöntem, indirgeyici ve sülfitleştirici bir atmosfer altında $\mathrm{CaCl}_{2}$ ve $\mathrm{CaCO}_{3}$ ile 1sitilmasidir. NTE fosfatlarının NTE oksisülfürlere $\left(\mathrm{NTE}_{2} \mathrm{O}_{2} \mathrm{~S}\right)$ ve oksiklorürlere (NTEOCl) dönüşmesine yol açarak kararl1 bir toryum oksit ve kloropatit $\left(\mathrm{Ca}_{5} \mathrm{Cl}\left(\mathrm{PO}_{4}\right)_{3}\right)$ oluşturmaktadır. NTE'leri karışımından \%3'lük $\mathrm{HCl}$ asit çözeltisi ile seçici olarak liç edilebilmektedir. Böylece toryumun neden olduğu çevresel tehdit ortadan kaldırılabilir. Ancak NTE'leri geri kazanım oranı alkali yöntemden daha düşüktür ve değerli bir yan ürün olan $\mathrm{Na}_{3} \mathrm{PO}_{4}$ bu proseste üretilmemektedir.
NTE'lerinin ksenotimden kazanımı için liç prosesleri uygulanmaktadir.

Ksenotim genellikle monazitin fiziksel zenginleştirilmesi sırasında yan ürün olarak elde edilmektedir. Ksenotimden NTE'lerinin ekstraksiyonu için sülfürik asit veya alkali liç prosesi kullanılmaktadır (Habashi, 2013).

Bastnazit mineralinde bulunan karbonatı uzaklaştırmak ve asit tüketimini azaltmak için, liç öncesi konsantrenin kavrulması gerekmektedir. Bastnazit mineral içeriğinin yarısı Ce olduğundan, ekstraksiyondan önce uzaklaştırılması, diğer NTE'lerinin seçimli olarak ayırmak için solvent ekstraksiyon kapasitesini önemli ölçüde azaltmaktadir. Kalsinasyon ile konsantreler başlangiçta Ce(III) 'ün Ce(IV)' e dönüştürülmekte ve diğer nadir toprak elementleri NTE(III) formunda kalmaktadır.

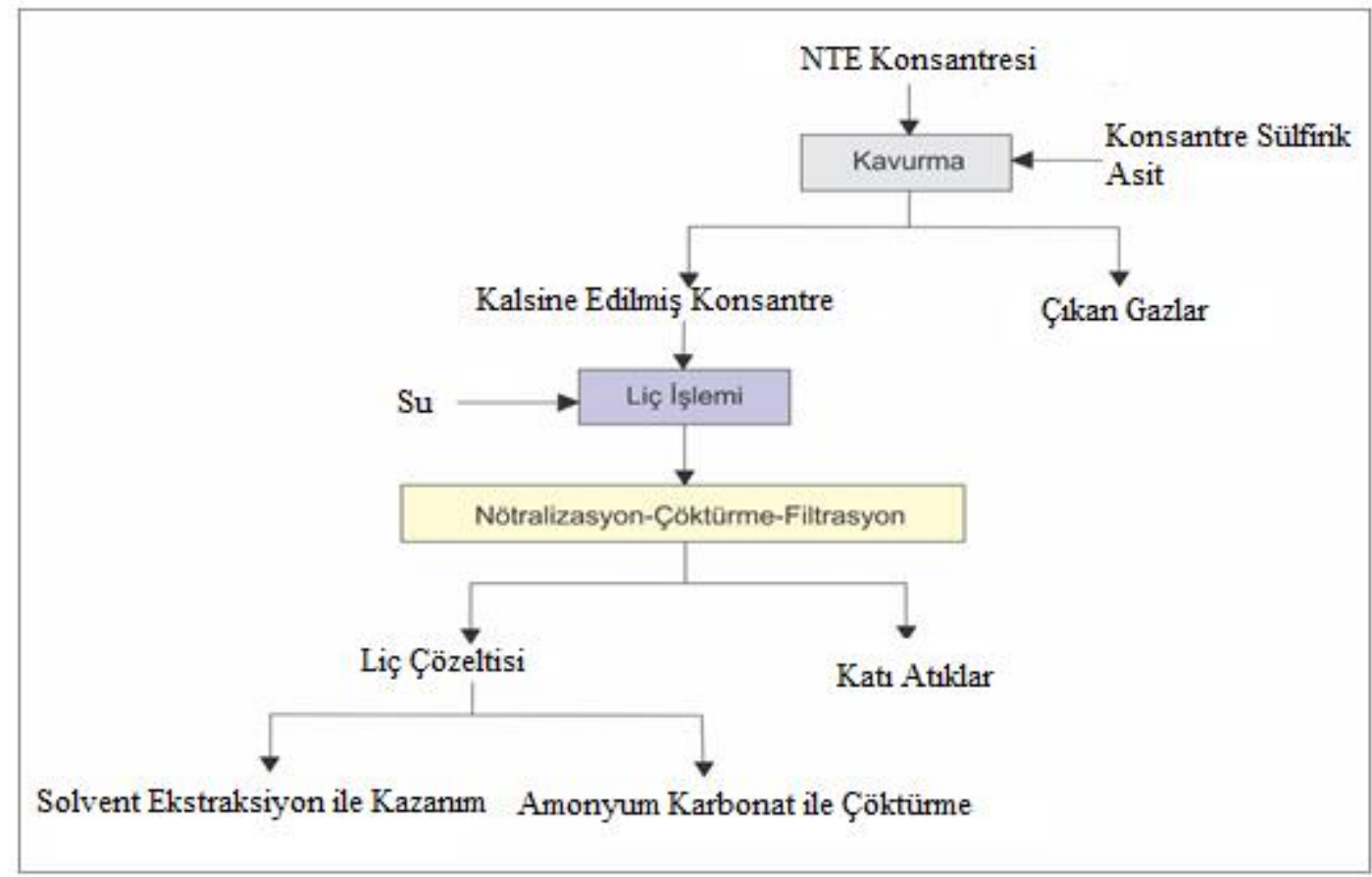

Şekil 2. Bastnazit için uygulanan liç prosesi (NTE: Nadir toprak elementleri) (Jha ve ark., 2016).

Hidroklorik asit ilave edilerek seryumun
çökmesi sağlanmakta ve filtre edilerek
kazanılmaktadır. Diğer tüm nadir toprak elementleri
çözeltiye geçmektedir. Elde edilen liç çözeltisi ayrıca
saf NTE bileşikleri elde etmek için çok kademeli
solvent ekstraksiyon yöntemleri kullanılmaktadır.
Bununla birlikte, ayırma maliyetlerini azaltmak için
Ce, asidik ortamda çözünmesini önleyen kavurma işlemine tabi tutularak $\mathrm{CeO}_{2}$ 'ye oksitlenir (Xie ve ark., 2014). Kimyasal proses reaktifleri arasinda inorganik asitler sülfürik asit, hidroklorik asit, nitrik asit, alkaliler $\left(\mathrm{NaOH}\right.$ ve $\left.\mathrm{Na}_{2} \mathrm{CO}_{3}\right)$ ve tuzlar $\left(\left(\mathrm{NH}_{4}\right)_{2} \mathrm{SO}_{4}, \mathrm{NH}_{4} \mathrm{CI}\right.$ ve $\left.\mathrm{NaCl}\right)$ bulunabilir. $\mathrm{H}_{2} \mathrm{SO}_{4}$ ve bazik kimyasallar genellikle monazit ve bastnazit gibi 
fosfat ve karbonat-florür cevherleri için kullanılmaktadır (Zhang ve Edwards, 2013). Bastnazit'in amonyum klorür ile kavrularak elde edilen formu sıcak suyla kolayca liç edilerek NTE klorürleri elde edilmiştir (Chi ve ark., 2004).

\section{Nadir Toprak Elementlerini Ayırma ve Saflaştırma}

NTE'lerinin sulu çözeltiden kazanımı, fiziksel ve kimyasal özelliklerinin büyük benzerliğinden dolayı birçok zorluk ortaya çıkarmaktadır. NTE oksitlerinin ticari değeri, her bir elementin etkin bir şekilde ayrılmasına dayanan bileşiğin saflığına ve kalitesine bağlıdır. Bu nedenle, liç çözeltilerinden saf NTE geri kazanımı için, seçici oksidasyon/indirgeme, fraksiyonel çöktürme, kristalizasyon, iyon değişimi ve SX işlemleri için sulu fazdaki türlerin bazikliği ve oluşumundaki farklılıklardan yararlanılarak ayırma işlemleri gerçekleştirilmektedir. Fraksiyonel kristallendirme ile karışımdaki bir veya daha fazla NTE'i, buharlaşma veya sıcaklık kontrolü yoluyla çözelti içindeki tuz konsantrasyonları değiştirilerek çöktürülür. Fraksiyonel çöktürme, bir metalin çözeltiden seçici bir şekilde uzaklaştırılması için bir çöktürücü reaktifin ilave edilmesini içermektedir.

NTE'lerinin çöktürülmesi, daha az çözünür bir bileşik oluşturmak için kimyasal bir reaktif ilave edilerek bu elementlerin bir kısmının çözeltiden ekstraksiyonunu ifade eder. NTE'lerinin çöktürme yoluyla ayrılması için hidroksitler ve çift sülfatlar yaygın olarak kullanılmaktadır. NTE'leri çift sülfatlar $\mathrm{NTE}_{2}\left(\mathrm{SO}_{4}\right)_{3} \cdot \mathrm{Na}_{2} \mathrm{SO}_{4} \cdot \mathrm{nH}_{2} \mathrm{O}$ genellikle konsantre çözeltiye sodyum sülfat ilavesiyle çöktürülür. Lantanyum, seryum, praseodiyum, neodmiyum ve samaryum gibi hafif NTE'leri az çözünür çift sülfatlardan elde edilirken, tüm ağır NTE'leri kompleksleri genel olarak çözünmektedir. NTE'lerinin çift olarak çökelmesi sülfatları tipik olarak nadir toprak hidroksitlerine $\left(\mathrm{NTE}(\mathrm{OH})_{3}\right)$ ve daha sonra metatez reaksiyonu yoluyla NTEO'lerine dönüştürülmektedir (Jha ve ark., 2016; Krishnamurthy ve Gupta, 2015).

NTE'lerinin seçimli çöktürülmesi genellikle okzalatlarla sağlanmaktadır. Örneğin toryum ve lantanitlerin monazit ve ksenotim konsantrelerinin sülfürik süzüntüsünden ayrılması genellikle okzalat ile çöktürülmesine dayanmaktadır. Toryum ve nadir toprak elementleri okzalatlar $\left(\mathrm{Th}\left(\mathrm{C}_{2} \mathrm{O}_{4}\right)_{2}\right.$ ve
$\left.\operatorname{NTE}\left(\mathrm{C}_{2} \mathrm{O}_{4}\right)_{3}\right) \quad \mathrm{NaOH}$ ile reaksiyona sokularak hidroksitlerine dönüştürülür. Oksitleri elde etmek için kalsine edilir ve SX yoluyla toryumun daha sonra ayrılması için kuvvetli asidik çözeltilerde çözülmektedir (Habashi, 2013). Çöktürme prosesine ait bazı çalışmalar Tablo 1'de verilmiştir (Jha ve ark., 2016).

İyon değişim yöntemi, iki elektrolit arasında veya bir elektrolit ile organik bir kompleks arasında iyon değişiminden oluşur. 1960'larda endüstriyel ölçekli SX'nun ortaya çıkmasından önce, iyon değiştirici reçine teknolojisi NTE'leri büyük miktarlarda ayırmanın tek pratik yolu olarak kullanılmıştır (Kumar, Thomas, ve Liz-Marzán, 2016; B. R. Reddy, Kumar, ve Radhika, 2009; W. D. Jamrack, 1964). Genellikle az miktarlarda oldukça saf NTE'i üretmek için kullanılır ve yüksek hacimli üretim için uygun değildir. Günümüzde iyon değişimi, yalnızca elektronik veya analitik uygulamalar için az miktarda yüksek saflıkta nadir toprak elementi elde etmek için kullanılmaktadır. İyon değiştirici reçineler fonksiyonel grupların cinsine göre dört farklı gruba siniflandırılabilir. $\mathrm{Bu}$ sınıflandırma i) Katyon değiştirici reçineler (asidik fonksiyonel gruplar $\left(-\mathrm{SO}_{3} \mathrm{H},-\mathrm{COOH}\right)$, ii) Anyon değiştirici reçineler (bazik fonksiyonel gruplar) ($\left.\mathrm{N}^{+} \mathrm{R}_{3} \mathrm{OH}^{-},-\mathrm{NH}_{2},=\mathrm{NH}, \equiv \mathrm{N}\right)$, iii) Amfoterik değiştirici reçineler (asidik ve bazik fonksiyonel gruplar), iv) Şelat yapıcı reçineler (şelat yapan fonksiyonel gruplar) $\left(-\mathrm{CH}_{2} \mathrm{~N}\left(\mathrm{CH}_{2} \mathrm{COOH}\right)_{2}\right.$ olarak verilebilir. Saflıkları \%99.999'u aşan NTE oksitlerini elde etmek için kullanılan iyon değişim yöntemidir, ancak daha az ekonomiktir (McGill, 2000). NTE'lerini sulu çözeltiden kazanmak için Tulsion CH-96, Amberlite XAD-4, T-PAR, Dowex I-28 ve D152 gibi birçok reçine kullanılmıştır. Tüm bu hidrometalurjik yöntemler arasında en yaygın olarak kullanılan solvent ekstraksiyon prosesidir. SX genellikle daha az miktarda seyreltik liç çözeltisinin işlenebilmesi nedeniyle NTE'lerini ayırmak için en uygun ticari teknoloji olarak kabul edilmektedir. Ekstraktantların seçimi NTE'lerinin sulu çözeltideki kimyasal formuna (NTE klorür, nitrat, sülfat veya oksitler) bağlıdır (Krishnamurthy ve Gupta, 2015; Reddy ve ark., 1993). Bu ayırma prosesinde, baziklikteki küçük farklılıklardan yararlanılır ve bu adımla NTE oksit içeriği \%99'dan fazla olabilmektedir. 
Tablo 1. Çöktürme proselerine ait bazı çalışmalar

\begin{tabular}{|c|c|c|}
\hline Kullanılan reaktif & Açıklama & Kaynak \\
\hline Sodyum sülfat & $\begin{array}{l}\text { Nadir toprak elementleri çift sülfat karışımı } 50^{\circ} \mathrm{C} \text { sıcaklıkta, } \\
\text { stoikiometrik } \mathrm{Na}_{2} \mathrm{SO}_{4} \text { miktarının } 1.25 \text { katı kullanılarak } \\
\text { üretilmiştir. Toplam nadir toprak elementleri çift sülfat } \\
\text { içeriği, az miktarda diğer safsızlıklar ile birlikte }>\% 90 \text { 'dır. }\end{array}$ & (Kul ve ark., 2008) \\
\hline Okzalik asit & $\begin{array}{l}\text { Diğer safsızlıklarla beraber NTE içeren liç çözeltisi okzalik } \\
\text { asit ile çöktürülerek NTE'lerinin okzalatlı çökelekleri elde } \\
\text { edilmiştir. Bu çökelek } 900^{\circ} \mathrm{C}^{\prime} \text { de } 1.5 \text { saat kavrularak NTEO } \\
\text { elde edilmiştir. }\end{array}$ & (Chi ve ark., 2000) \\
\hline $\begin{array}{l}\text { Hidroksit-Okzalat } \\
\text { karışımı }\end{array}$ & $\begin{array}{l}\text { Kavrulmuş ön-konsantre bastnazit cevherinin liç edilmesiyle } \\
\text { toplamda \%89'luk NTE içeren filtrat elde edilmiştir. NTE } \\
\text { içeriğinin \%93.6'sı hidroksit-okzalat karışımı ile } \\
\text { çöktürülmüş ve } 900^{\circ} \mathrm{C}^{\prime} \text { de } 2 \text { saat kavrularak NTEO } \\
\text { dönüştürülmüştür. }\end{array}$ & $\begin{array}{l}\text { (Yörükoğlu ve ark., } \\
\text { 2003) }\end{array}$ \\
\hline Amonyum hidroksit & $\begin{array}{l}\text { Amonyum hidroksit, } 7.9 \text { ila } 9.6 \text { arasında değişen pH'larda } \\
\text { lantanyum hidroksit olarak lantanyumu çöktürmek için } \\
\text { kullanılmıştır. Üç kez çöktürme yapılarak \%96’lık } \\
\text { lantanyum oksit kazanılmıştır. }\end{array}$ & $\begin{array}{l}\text { (Lwin Thuza Shwe, } \\
\text { Nwe Nwe Soe, 2008) }\end{array}$ \\
\hline Amonyak & $\begin{array}{l}\text { Lantanyum nitrat suda çözülmüş ve } \mathrm{pH} \sim 10 \text { 'a ulaşılancaya } \\
\text { kadar } 2 \mathrm{M} \text { 'lık amonyak çözeltisi damla damla ilave edilerek } \\
\text { lantantum hidroksite ve oksit hazırlanmıştır. }\end{array}$ & (Kim ve ark., 2008) \\
\hline $\begin{array}{l}\text { Sodyum hidroksit, } \\
\text { amonyum hidroksit ve } \\
\text { potasyum hidroksit }\end{array}$ & $\begin{array}{l}\text { Neodimyumun çift tuzu, sodyum hidroksit, amonyum } \\
\text { hidroksit ve potasyum hidroksit kullanılarak elde edilmiştir; } \\
\text { Ayrıca neodimyum florür oluşturmak için HF asit ile liç } \\
\text { edilmiştir. }\end{array}$ & $\begin{array}{l}\text { (Lyman ve Palmer, } \\
\text { 1993) }\end{array}$ \\
\hline
\end{tabular}

Bununla birlikte, NTE'leri arasındaki baziklik farkları küçük olduğu için, her bir NTE oksitlerini ayırmak hem zaman alıcı hem de maliyetli olmaktadır. Her bir NTE'lerini ayırmak için çok kademeli SX prosesi oldukça yaygin bir şekilde kullanılmaktadır. NTE oksitleri Y'nin ayrılması, Ce ekstraksiyonu $\left(\mathrm{Ce}^{4+}\right)$ ve $\mathrm{Eu}\left(\mathrm{Eu}^{2+}\right)$ ayırmas1, istenen her bir NTE'inin ayrılması yoluyla üç aşamada SX'yla kazanılmaktadır (Krishnamurthy ve Gupta, 2015).

Solvent ekstraksiyon işleminde, asidik/alkali liç çözeltilerinden NTE'leri ayrılması ve saflaştırılması sırasında oluşan ürünlerin kalitesini etkileyen $\mathrm{Ca}^{2+}$, $\mathrm{Fe}^{3+}, \mathrm{Al}^{3+}, \mathrm{Pb}^{2+}$, vb. gibi safsızlıklar çöktürme yöntemiyle uzaklaştırılmaktadır (Krishnamurthy ve Gupta, 2015). Tablo 2'de verilen Tulsion CH-96, Tulsion CH-93, T-PAR ve IR-120P gibi farklı iyon değişim reçineleri kullanarak NTE'lerini ekstrakte etmek için çeşitli araştırmacılar tarafından gerçekleştirilmiştir (Jha ve ark., 2016). Liç çözeltileri genellikle birden fazla metal iyonu içerir. Solvent ekstraksiyon prosesi liç çözeltilerinden seçimli olarak metal iyonlarının kazanılmasında veya çözeltinin saflaştırılması için kullanılan yöntemlerden biridir.
Solvent ekstraksiyon tekniklerine dayalı ayırma işlemleri, yüksek saflıkta NTE'leri içeren çözeltileri veya bileşikleri üretmek için geliştirilmiştir (Xie ve ark., 2014). SX genellikle NTE'lerini ayırmak için en uygun ticari teknolojik proses olarak kabul edilmektedir. Metal iyonlarını sulu fazdan organik faza transfer etmek için çok sayıda temas gerekir. Bu aynı zamanda, yüklü organik fazın, değerli türlerin geri kazanılması ve kütle dengesinin oluşması için sulu bir çözelti ile temas ettiği sıyırma aşaması için de geçerlidir. SX, ekstrakte edici, seyreltici, modifiye edici ve sinerjist olmak üzere dört bileşene bölünmüştür. Ekstraktant veya kompleks yapıcı ligand, ekstraksiyon işleminde aktif rol oynayan ana ekstraktant olup organik fazın solvent odak bileşenidir. Seyrelticinin işlevi, ekstraktantın viskozitesini azaltmak ve böylece sistemin hidrodinamik özelliklerini iyileştirmektir (Chiranjib Kumar Gupta, 2003). Toluen, karbon tetraklorür, ksilen, kloroform, propanol, kerosen ve heptan gibi tipik seyrelticiler yüksek buhar basıncına sahiptir ve yanıcıdır (Li ve ark., 2007; Sarangi, Reddy, ve Das, 1999; Shariati ve Yamini, 2006). Bu geleneksel seyrelticilere alternatif olarak, daha sonra 
[C4mim][NTf2] (Rout ve Binnemans, 2014) ve [A336][NO3] (Sun ve ark., 2011) gibi iyonik sıv1lar ile yer değiştirmiştir. İyonik sıvıların ihmal edilebilir buhar basincina sahiptir, ancak maliyet ve viskozite açısından yüksek değerlere sahiptir. Seyreltici, ekstraktant ile homojen olmalı, ancak kirlenmeyi önlemek için sulu çözelti içinde karışmamalıdır (Atanassova ve ark., 2016; Sun, Luo, ve Dai, 2012). Modifiye edici, ekstraksiyon aşamasında üçüncü faz veya emülsiyon oluşumunu önlemek için kullanılan bir çözücüdür (Gupta, 2003). Emülsiyon normalde iki karışmayan çözücü karıştırıldığında ve çalkalandığında oluşmaktadır (Pospiech ve Kujawski, 2015; Sun ve ark., 2012). Sürekli bir sistemde emülsiyon, zayıf akış hızı ve zayıf viskozite kontrolünden kaynaklanmaktadır. $\mathrm{NaNO}_{3}$, üçüncü faz oluşumunu stabilize etmek için sulu çözeltiye ilave edilmektedir (Rout ve Binnemans, 2014). İzodekanol, 2-etilheksanol, nonilfenol ve tributil fosfat (nötr ekstraktant) gibi uzun zincirli alkil alkoller de modifiye edici kimyasallara örnek olarak verilebilir (Gupta, 2003). Sinerjik ekstraktant son zamanlarda ayırmayı, seçimliliği arttırmak ve emülsiyon oluşumunu önlediği için yaygın bir şekilde kullanılmaktadır. Sinerjistik ekstraktant, yeni bir dinamik çözücü oluşturmak için iki veya daha fazla çözücünün bir kombinasyonudur. Sinerjistik ekstraktant, bireysel ekstraktantlara kıyasla daha iyi ekstraksiyon ve seçicilik verimliliği sağladığı tespit edilen iki işlevli çözücü olarak da bilinmektedir. CA12-Cyanex272, HEHEHP- D2EHPA; Cyanex 272$\mathrm{D}_{2}$ EHPA ve Cyanex 302- $\mathrm{D}_{2}$ EHPA, NTE ekstraksiyonunda kullanılan sinerjistik ekstraktant örnekleridir. Sinerjistik ekstraktant SX, modifiye edici ve seyrelticinin bir kombinasyonu da olabilir. SX'nun ana dezavantajı, ekstraksiyonda yüksek bir verimlilik ve istenen elementin seçiciliğine ulaşmadaki zorluktur (Hidayah ve Abidin, 2017; Xie ve ark., 2014).

\section{ekstraktantların sınıflandırılması:}

Asidik ekstraktantlar, nötr ekstraktantlar ve bazik ekstraktantlar olmak üzere üç ana ekstraktant sınıfının tümü, NTE'lerini ayırmak için kullanılmıștır. Tablo 3'de SX'nda kullanılan bazı ticari ekstraktantlar verilmiştir (Xie ve ark., 2014). SX'nu niceliksel olarak tanımlamak için yaygın olarak kullanılan dağılım katsayısı (Eşitlik 7) ve ayırma faktörü (Eşitlik 8) olmak üzere iki terimi tanımlamak yararlı olacaktır. Bir metal iyonunun dağılım katsayısı $\mathrm{D}_{\mathrm{M}}$, organik fazdaki metal iyonunun molar derişimi $[\mathrm{M}]_{\text {org }}$, sulu fazdaki metal iyonunun derişimi $[\mathrm{M}]_{\text {aq. }}$ temsil etmektedir.

Tablo 2. İyon değişim prosesi kullanılarak nadir toprak elementlerinin ekstraksiyonu

\begin{tabular}{|c|c|c|}
\hline $\begin{array}{c}\text { Ticari olarak } \\
\text { kullanılan reçine adı }\end{array}$ & Belirgin özellikleri & Kaynaklar \\
\hline $\begin{array}{l}\text { Tulsion CH-96 and } \\
\text { T-PAR }\end{array}$ & $\begin{array}{l}\text { Tulsion CH-96 ve T-PAR reçineleri kullanılarak } \\
\text { fosforik asitten Tb, Dy, Ho, Y, Er, Yb ve Lu gibi } \\
\text { ağır nadir toprak elementlerinin ekstrakte edildiği } \\
\text { belirtilmiştir. }\end{array}$ & $\begin{array}{l}\text { (Nagaphani Kumar ve ark., } \\
\text { 2010) }\end{array}$ \\
\hline IR-120P & $\begin{array}{l}\text { IR-120P katyon değişimli polimerik reçine } \\
\text { kullanılarak klorürlü ortamından Y ve nadir } \\
\text { toprak elementlerinin kazanımı rapor edilmiştir. }\end{array}$ & (Pinto ve Martins, 2001) \\
\hline $\begin{array}{l}\text { N-metilimidazolyum } \\
\text { işlevselleştirilmiş } \\
\text { anyon değişim } \\
\text { reçinesi }\end{array}$ & $\begin{array}{l}\mathrm{Ce}^{4++} \text { ün nitrik asitli ortamından } \mathrm{Ce}^{3+1} \mathrm{e} \\
\text { indirgenerek adsorpsiyonu için } \mathrm{N}- \\
\text { metilimidazolyum fonksiyonelleştirilmiş anyon } \\
\text { değişim reçinesi kullanılmıştır. }\end{array}$ & (Zhu ve Chen, 2011) \\
\hline Tulsion CH-93 & $\begin{array}{l}\text { Tulsion CH-93 (Amino fosfonik asit reçinesi) } \\
\text { kullanılarak fosforik asitli ortamından Gd'nin } \\
\text { ekstrakte edildiği belirlenmiştir. }\end{array}$ & (Radhika ve ark., 2012) \\
\hline $\begin{array}{l}\text { Dowex I-X8 anion- } \\
\text { exchange resin }\end{array}$ & $\begin{array}{l}\text { Dowex-I-X8 reçinesinin kullanıldığı iyon değişim } \\
\text { kromatografisi ile nadir toprak elementlerinin } \\
\text { ayrılması için yeterli olduğu bulunmuştur. }\end{array}$ & (Alstad ve Brunfelt, 1967) \\
\hline
\end{tabular}




\begin{tabular}{|c|c|c|}
\hline D113-III resin & $\begin{array}{l}\text { D113-III reçinesi kullanılarak Er(III) iyonunun } \\
\text { adsorpsiyon ve desorpsiyon davranışları } \\
\text { incelenmiştir. Er (III) iyonunun D113-III üzerine } \\
\text { yüklenmesi, başlangıç derişiminin artmasıyla } \\
\text { artmıştır. }\end{array}$ & (XIONG ve ark., 2009) \\
\hline $\begin{array}{l}\text { D72 (acid ion } \\
\text { exchange resin) }\end{array}$ & $\begin{array}{l}\text { Pr(III) iyonlarının adsorpsiyonu çözeltinin pH } \\
\text { değerine ve adsorpsiyon kinetiğinin yalanc1- ikinci } \\
\text { dereceden kinetik modele uyduğu, } 298 \text { K'de } \\
\text { langmuir modeli için adsorpsiyon kapasitesi } 294 \\
\text { mg.g }{ }^{-1} \text { olarak bulunmuştur. }\end{array}$ & (Xiong ve ark., 2012) \\
\hline D151 resin & $\begin{array}{l}\mathrm{Ce}^{3+1} \text { ün D151 reçinesi üzerindeki adsorpsiyon ve } \\
\text { desorpsiyon davranışları HAc-NaAc ortamında } \\
\text { pH 6.50'da elde edilmiştir. } \\
\mathrm{Ce}^{3+} \text { 'ün maksimum adsorpsiyon kapasitesi } 298 \\
\mathrm{~K}^{\prime} \text { de } 392 \mathrm{mg} . \mathrm{g}^{-1} \text { olarak belirlenmiştir. }\end{array}$ & $($ Yao, 2010) \\
\hline $\begin{array}{l}\text { Bio-Rad AG 50W-X2 } \\
\text { cation-exchange resin }\end{array}$ & $\begin{array}{l}\text { Bio-Rad AG 50W-X2 reçinesi kullanılarak Y ve } \\
\text { nadir toprak elementlerinin mono- ve di-floro } \\
\text { kompleksleri için kararlılık sabitlerini belirlemek } \\
\text { için yeni bir yöntem ortaya konmuştur. }\end{array}$ & (Schijf ve Byrne, 1999) \\
\hline Amberlite XAD-4 & $\begin{array}{l}\mathrm{La}^{3+}, \mathrm{Nd}^{3+} \text { ve } \mathrm{Sm}^{3+} \text { iyonlarını içeren sentetik bir } \\
\text { çözeltisi ön konsantrasyonu ve ayrılması, } \\
\text { monoazadibenzo 18-taç-6 eter ile Amberlite } \\
\text { XAD-4 kullanılarak gerçekleştirilmiştir. Adsorbe } \\
\text { edilmiş nadir toprak elementleri, } 2 \mathrm{M} \mathrm{HCl} \mathrm{ile} \\
\text { sıyrılmıştır. }\end{array}$ & (Dave ve ark., 2010) \\
\hline
\end{tabular}

Tablo 3. Nadir toprak elementlerinin ekstraksiyonunda kullanılan bazı ticari ekstraktantlar

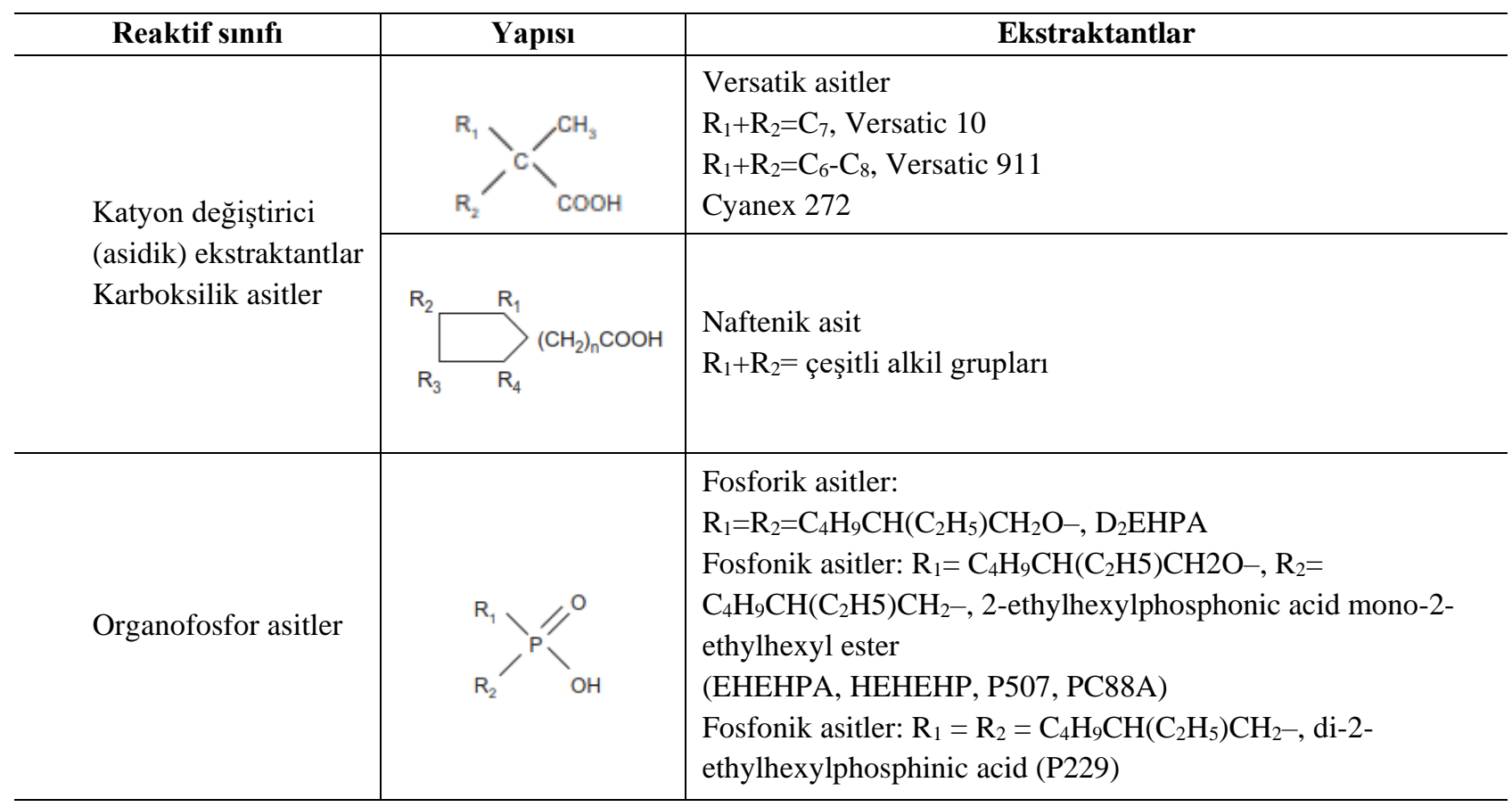




\begin{tabular}{|c|c|c|}
\hline & & $\begin{array}{l}\mathrm{R}_{1}=\mathrm{R}_{2}=\mathrm{CH} 3(\mathrm{CH} 2) 3 \mathrm{CH} 2 \mathrm{CH}(\mathrm{CH} 3) \mathrm{CH} 2-, \text { di-2,4,4- } \\
\text { trimethylpentylphosphinic acid (Cyanex 272) }\end{array}$ \\
\hline & $\mathrm{R}_{2}^{\mathrm{R}_{1}} /{ }_{\mathrm{PH}}^{\mathrm{S}}$ & $\begin{array}{l}\text { Monotiyofosforöz asitler: } \mathrm{R}_{1}=\mathrm{R}_{2}= \\
\mathrm{CH}_{3}\left(\mathrm{CH}_{2}\right)_{3} \mathrm{CH}_{2} \mathrm{CH}\left(\mathrm{CH}_{3}\right) \mathrm{CH}_{2}-\text {, di-2,4,4-trimethylpentyl- } \\
\text { monothiophosphinic acid (Cyanex 302) }\end{array}$ \\
\hline & $\mathrm{R}_{2}^{\mathrm{R}_{1}} \overbrace{\mathrm{SH}}^{\mathrm{P}}$ & $\begin{array}{l}\text { Ditiyofosforöz asitler: } \mathrm{R}_{1}=\mathrm{R}_{2}=\mathrm{CH}_{3}\left(\mathrm{CH}_{2}\right)_{3} \mathrm{CH}_{2} \mathrm{CH}\left(\mathrm{CH}_{3}\right) \mathrm{CH}_{2}- \\
\text {, di-2,4,4-trimethylpentyl-dithiophosphinic acid (Cyanex 301) }\end{array}$ \\
\hline $\begin{array}{l}\text { Şelatlayıcı } \\
\text { ekstraktantlar }\end{array}$ & $\mathrm{R}_{1} \prod_{\mathrm{O}}^{\mathrm{O}} \mathrm{CH}_{2} \underset{\|}{\mathrm{C}} \mathrm{R}_{2}$ & $\begin{array}{l}\beta \text {-diketonlar: } \mathrm{R}_{1}=\mathrm{R}-\mathrm{C}_{6} \mathrm{H}_{5}, \mathrm{R}_{2}=\mathrm{CH}_{3}\left(\mathrm{CH}_{2}\right)_{5}-, \mathrm{R} \text { : bilinmeyen } \\
\text { alkil grubu, (LIX 54, Kelex 100) }\end{array}$ \\
\hline $\begin{array}{l}\text { Nötral (Solvasyon) } \\
\text { ekstraktantlar }\end{array}$ & $\mathrm{R}_{2}$ & $\begin{array}{l}\text { Fosforöz esterler: } \mathrm{R}_{1}=\mathrm{R}_{2}=\mathrm{R}_{3}=\mathrm{CH}_{2}\left(\mathrm{CH}_{2}\right)_{2} \mathrm{CH}_{2} \mathrm{O}-\text {, tri-n- } \\
\text { butyl-phosphate (TBP) } \\
\mathrm{R}_{1}=\mathrm{R}_{2}=\mathrm{CH}_{2}\left(\mathrm{CH}_{2}\right)_{2} \mathrm{CH}_{2} \mathrm{O}-, \mathrm{R}_{3}=\mathrm{CH}_{2}\left(\mathrm{CH}_{2}\right)_{2} \mathrm{CH}_{2}-\text {, } \\
\text { dibutylbutylphosphonate (DBBP) } \\
\text { Fosfin oksit ekstraktantlar: } \mathrm{R}_{1}=\mathrm{R}_{2}=\mathrm{R}_{3}=\mathrm{CH}_{2}\left(\mathrm{CH}_{2}\right)_{6} \mathrm{CH}_{2}-\text {, } \\
\text { tri-n-octylphosphine oxide (TOPO, Cyanex } 921 \text { ) }\end{array}$ \\
\hline \multirow[b]{2}{*}{$\begin{array}{l}\text { Anyonik (bazik) } \\
\text { ekstraktantlar }\end{array}$} & $\mathrm{RNH}_{2}$ & $\begin{array}{l}\left.\text { Birincil aminler: } \mathrm{R}=\left(\mathrm{CH}_{3}\right)_{3} \mathrm{C}(\mathrm{CH})_{2} \mathrm{C}\left(\mathrm{CH}_{3}\right)_{2}\right)_{4} \text { (Primene JMT, } \\
\text { N1923) }\end{array}$ \\
\hline & $\mathrm{R}_{2}^{\mathrm{R}_{1}} \overbrace{\mathrm{R}_{3}}^{\mathrm{CH}_{3} \mathrm{Cl}}$ & $\begin{array}{l}\text { Kuaterner aminler: } \mathrm{R}_{1}=\mathrm{R}_{2}=\mathrm{R}_{3}=\mathrm{C}_{8}-\mathrm{C}_{10} \text { mixture (Aliquat } \\
\text { 336, Adogen 464) }\end{array}$ \\
\hline
\end{tabular}

$D_{M}=\frac{[M]_{\text {org. }}}{[M]_{\text {aq }}}$

İki farklı metal iyonunun ayırma faktörü ise şu şekilde tanımlanır:

$\beta_{M_{1} / M_{2}}=\frac{D_{M_{1}}}{D_{M_{2}}}$

NTE'lerinin, sulu ortamdan katyonik ekstraktantları ile genel ekstraksiyonu genel olarak şu şekilde ifade edilebilir (Xie ve ark., 2014):

$L n^{3+}+3 H A \leftrightarrow L n A_{3}+3 H^{+}$

Burada, Ln herhangi bir NTE'i türünü, A organik anyonu ve organik fazda bulunan türleri temsil etmektedir. Dünya'da farklı çözelti ortamlarından nadir toprak elementlerini etkin bir şekilde ayırmak için farklı organik ekstraktantlar kullanılarak solvent ekstraksiyon prosesiyle nadir toprak elementlerinin ekstraksiyonu için kapsamlı çalışmalar yapılmıştır. NTE'lerinin katyonik ekstraktantlarla ekstraksiyonunun sulu faz pH'ının artmasıyla artmaktadir, ekstraksiyon reaksiyonunu tersine çeviren sıyırma işleminin ise sulu sıyırma çözeltisinin asitliğini artırarak desteklenmektedir.
Nadir toprak elementlerini ayırmaları için karboksilik asitler, organofosfor asitler ve glikol amit asit türevleri kullanılabilir. $\mathrm{Bu}$ ekstraktantlar diğer sınıflara kıyasla yüksek verimliliğe sahiptir. NTE'lerinin ekstraksiyonu 3 ila $5 \mathrm{pH}$ değerlerinin altında gerçekleştirilir ve bu nedenle, $\mathrm{H}^{+}$çakışması genellikle sulu çözeltiden asidik alanlar ile asidik katyonik ekstraktantlarda bulunan bağlanma bölgeleri arasında meydana gelir ve sonuç olarak metal iyonlarının ekstraksiyonunu etkilemektedir (Hidayah ve Abidin, 2017). Karboksilik asitler pH 67.5 altında ekstraksiyon oldukça etkilidir. Karboksilik asit ayrışması çok düşük pH'lı bir çözeltide zayıftır (Gupta, 1981). Bununla birlikte, karboksilik asit geniş bir ekstraksiyon seçeneğine sahiptir ve ana malzemeler ve ticari isimlere göre sınıflandırılmaktadır. NTE'lerinin ekstraksiyonunda genellikle naftenik asit, versatik asit ve asetik asit gibi karboksilik asitler kullanılmaktadır.. Versatic 10 genellikle N,N-dioktildiglikol amik asit (DODGAA) ile karşılaştırılır çünkü her iki çözücü de karbon, hidrojen, oksijen ve nitrojen (CHON) bazlı ekstraktantlardir (Shimojo, Nakai, Okamura, Ohashi, ve Naganawa, 2013). Versatic 911, La-Ce ve Ce-Pr 
için sırasıyla 3 ve 1.6 ayırma faktörüne ve tributil fosfattan (TBP) daha iyi performansa sahip olduğu (Krishnamurthy ve Gupta, 2015), ancak, sirasiyla 3.95 ve 1.64 ayırma faktörü ile Versatic 10 ile karşılaştırıldığında daha az etkili olduğu belirlenmiştir (Singh, Singh, ve Mathur, 2006). Nötr ekstraktantlar kullanilarak yapılan ekstraksiyonda, ekstraksiyon maddesi hidrofobik türler oluşturmak için metal iyonunun hidrasyon kabuğundan koordineli su moleküllerini değiştirmekte ve böylece onları organik faza taşınır. NTE'leri için bu durum Eşitlik 10 ile ifade edilmektedir:

$$
\mathrm{MA}_{3 .} x \mathrm{H}_{2} \mathrm{O}_{(\text {aq) }}+3 \mathrm{~S}_{(\text {org) }} \leftrightarrow \mathrm{MA}_{3} .3 \mathrm{~S}_{(\text {org) }}+x \mathrm{H}_{2} \mathrm{O}
$$

M'nin üç değerlikli lantanit olduğu durumda, $\mathrm{A}, \mathrm{Cl}^{-}$, $\mathrm{NO}^{3-}, \mathrm{SO}_{4}{ }^{2-}$ gibi anyonları göstermektedir ve $\mathrm{S}$, çözücü veya nötr ekstraktantı temsil etmektedir. Lantanit komplekslerinin stabilitesi ve bunların ekstrakte edilme eğilimleri $\mathrm{La}^{3+}$ 'dan $\mathrm{Lu}^{3+}$ e yükselir. $\mathrm{Bu}$ durum, katyonik yarıçaptaki azalmaya atfedilmektedir (A Akcil, 2019), çünkü metal iyonu ile ligand arasındaki elektrostatik etkileşim, katyonik yarıçap ile ters orantılı olarak değişmektedir. Sterik etki, belirli bir katyon boyutundan sonra elektrostatik etkilere ağır basmaktadır. Nötr organofosfor bileşiklerinin ekstraksiyon verimliliği genellikle şu siray1 takip eder: fosfin oksitler $>$ fosfinatlar $>$ fosfonatlar $>$ fosfatlar. Üç alkil grubunun kümülatif pozitif indüktif etkilerinden dolayı fosfin oksitteki fosforil oksijenin bazikliğindeki artışa atfedilmektedir (A Akcil, 2019). Nötr ekstraktantlar olarak siniflandirılan fosfin oksitler, NTE'lerinin ayrıştırılması ve saflaştırılmasında büyük önem taşımaktadır. Daha fazla stabilite, daha az suda çözünürlük ve hızlı faz ayrılması sergilerler. Cyanex 923 kullanılarak itriyum ile birlikte üç değerlikli nadir toprak iyonlarının ekstraksiyon performans1 değerlendirilmiş ve ortaya çıkan kompleksi Ln $\left(\mathrm{NO}_{3}\right)_{3} \cdot 2$ Cyanex 923 olarak önerilmiştir (B. Gupta, Malik, ve Deep, 2003). Toluende seyreltilmiş Cyanex 921 yardımıyla nitrat çözeltisinden $\mathrm{Eu}^{3+}$ 'ün sıv1-sıvı ekstraksiyonu incelenmiştir (Awwad, Gad, ve Aly, 2008). Anyon değiştirici ekstraktantlar, metal iyonlarını anyonik kompleksler olarak çıktığı ve güçlü iyonik çözücülerin varlığında etkili olduğu belirtilmiştir (Krishnamurthy ve Gupta, 2015). Siv1 anyon değiştiriciler uzun zincirli alkali aminler olarak bilinmektedir ve birincil $\left(\mathrm{RNH}_{2}\right)$, ikincil $\left(\mathrm{R}_{2} \mathrm{NH}\right)$, üçüncül $\left(\mathrm{R}_{3} \mathrm{~N}\right)$ ve kuaterner amonyum halojenürler olarak sınıflandırılmaktadır. Birincil ve üçüncül amin kullanan anyon değiştiricinin seçicilik etkinliği, klorür ortamında zayıf kabul edilmekte, ancak ayırma performansı sülfat ortamında dah iyi olduğu belirtilmiştir. Aminlerin anyon değiştiricileri olarak hareket edebilmeleri için protonasyona ihtiyaçlarından kaynaklanmaktadır (Chiranjib Kumar Gupta, 2003). Anyon değiştiricilerden Aliquat 336 (A336) hafif NTE'lerini ağır NTE'lerinden daha iyi ekstrakte ettiği tespit edilmiştir (Xie ve ark., 2014). A336, katyonik ve nötral ekstraktantlar ile karşılaştırıldığında NTE'i ekstraksiyonunda zıt seçicilik ekstraksiyon etkisine sahip olmaktadır (Xie ve ark., 2014). Birincil ve ikincil aminler genellikle NTE'leri için zayıf ekstraksiyon maddeleridir ve etkili ayırma için yüksek asit ve tuz molariteleri gerekmektedir (Bauer, 1966). Tersiyer aminler de etkili ekstraktantlar olmadı $\breve{g}_{1}$ ifade edilmektedir (A Akcil, 2019). La(III)'ün sülfat çözeltisinden, amino grubunun bir üçüncül karbon atomuna bağlı olduğu Primen JMT ticari birincil amin karışımı ile ekstraksiyonu çalışması aşağıdaki eşitliklerde verilmiştir:

$2 \mathrm{RNH}_{2}+\mathrm{H}_{2} \mathrm{SO}_{4} \rightarrow\left(\mathrm{RNH}_{3}\right)_{2} \mathrm{SO}_{4}$

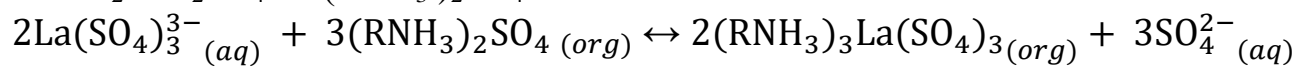

Metal ekstraksiyonunda şelatlayıcı ekstraktantlar yaygin olarak kullanılmakta, ancak NTE ekstraksiyonunda uygulamada pratik olmadığ 1 için tercih edilmemektedir. Şelatlayıcı ekstraktantın temel özelliği, ekstraktant molekül içinde metal iyonlarına ligand görevi gören halka yapısının varlığıdır. 2thenoyltri fluoroaseton (HTTA) ve 4-benzoil-3-metil1-fenil-2-pirazolin-5-on (HP) şelatlayıc1 ekstraktantlara örnek olarak verilmektedir. Bununla birlikte, şelatlayıcı ekstraktant NTE ekstraksiyonunda katyonik ekstraktanta kıyasla zayıf performansa sahiptir (Xie ve ark., 2014). Bu ekstraktantlar, ekstraktantın etki ettiği zamana kıyasla 4-(2-piridilazo)-resorsin ile sinerjistik etkisi ile daha iyi performans gösterdiği belirlenmiştir (Atanassova, 2006). Ağır NTE'lerinin ve hafif NTE'lerinin damıtılmış kerosende TOPS 99 yardımıyla fosforik 
asit çözeltisinden ayrılması için bir işlem akış şeması Şekil 3'de sunulmuştur (Radhika ve ark., 2011).

NTE'lerinin solvent ekstraksiyon yöntemiyle kazanımı için, di-2-etilheksil-fosforik asit $\left(\mathrm{D}_{2} \mathrm{EHPA}\right.$ veya P204), 2-etilheksil fosfonik asit mono-2etilheksil ester (HEH/EHP, PC-88A, P507, Ionquest 801) (Chang ve ark., 2010; Radhika ve ark., 2011; Wang ve ark., 2014), naftenik asit, versatik asit, trialkil-metil amonyum klorür (Aliquat 336), Bis (2,4,4-trimetilpentil) fosfinik asit (Cyanex 272), tributil fosfat (TBP), vb. ekstrakstantları endüstride yaygın olarak kullanılmaktadır. $\mathrm{D}_{2} \mathrm{EHPA}$ nitrat, sülfat, klorür ve perklorat içeren çözeltilerinden NTE'lerinin ayrımı için en çok çalışılan ekstraktantlardan biridir. NTE'lerini sulu çözeltilerden ekstraksiyon için, sabunlaştırılmış PC88A'nın klorür çözeltilerinde, nitratlı çözeltilerde tributil fosfat (TBP) kullanılmıștır (Krishnamurthy ve Gupta, 2015; Thakur, 2000). Sulu çözeltiden NTE'lerinin oluşturduğu anyonik kompleksler, aminbazlı ekstraktantlar kullanılarak ekstrakte edilir. Bazı NTE'leri (Eu ve Ce) seçici olarak ayrılması, sulu çözeltideki değerlik durumlarına göre yapılmaktadır. Uzun zincirli quaterner amonyum tuzları, yüksek saflıkta itriyumun (Y) ayırma ve saflaştırma için ticari ölçekte kullanılmıştır. Farklı hafif ve ağır NTE'lerinin (Dy, Y, Gd, Er, Ho, vb.) katyonik, anyonik ve solvate ekstraktantlar ile klorürlü ortamlardan ayrılması kapsamlı bir şekilde incelenmiştir. Katyonik ekstraktantlar söz konusu olduğunda, NTE'lerinin ekstraksiyonu, çözeltilerin asitliğine bağlıdır. D2EHPA ve PC-88A, NTE'lerinin klorür içeren ortamdan ayrılması için en uygun ekstraktantlar olarak kabul edilmiştir. Lantanitlerin metal iyonlarının önemli ölçüde ekstraksiyonu ve ayrılması, üçüncül ve dördüncül aminler kullanılarak da gerçekleştirilebilir. Ayrıca, bir metal iyonunun ekstraksiyon etkinliğinin, özellikle Y(III) ve ağır NTE'leri arasında trialkil fosfin oksit ilavesi üzerine arttığ 1 belirlenmiştir. Alkil ve aril sülfoksitler, tri-noctyl phosphine oxide (TOPO) ve 2thenoyltrifluoroacetone (TTA)'nın, tiyosiyanat çözeltisinden Ce ekstraksiyonu, La için ise TOPO ve Dibenzyl sulphoxide (DBSO) kullanılarak ekstraktsiyonlarının uygun olduğu ifade edilmiş (Guru ve ark., 2011), NTE(III) iyonlarının, tiyosiyanat çözelti ortamında ekstraksiyonu, nitratlı ortamdan ekstraksiyonlarına kıyasla daha iyi seçicilik sağladığı ve etkin bir şekilde ayırmanın yapıldığını çalışmalar göstermiştir (A. S. Reddy ve Reddy, 1977). Fosforik asitli ortamdan TOPS-99, PC-88A ve Cyanex 272 ekstraktantları kullanılarak ağır nadir toprak elementlerini (Tb, Dy, Ho, Y, Er, YB ve Lu) ve hafif ağır nadir toprak elementlerini ( $\mathrm{La}, \mathrm{Ce}, \mathrm{Pr}$, $\mathrm{Nd)}$ ayırmak için yapılan solvent ekstraksiyon çalışmalarında, ekstraksiyon verimliliğinin TOPS-99 $>$ PC-88A > Cyanex 272 siralamasina göre etkin olduğu belirlenmiştir (Radhika ve ark., 2010). Ekstraktantların genellikle sulu faz ile iyi temas sağlamak için farklı taşıyıcı ortamlarda karışmaları sağlanmıştır. Solvent ekstraksiyon sisteminin 


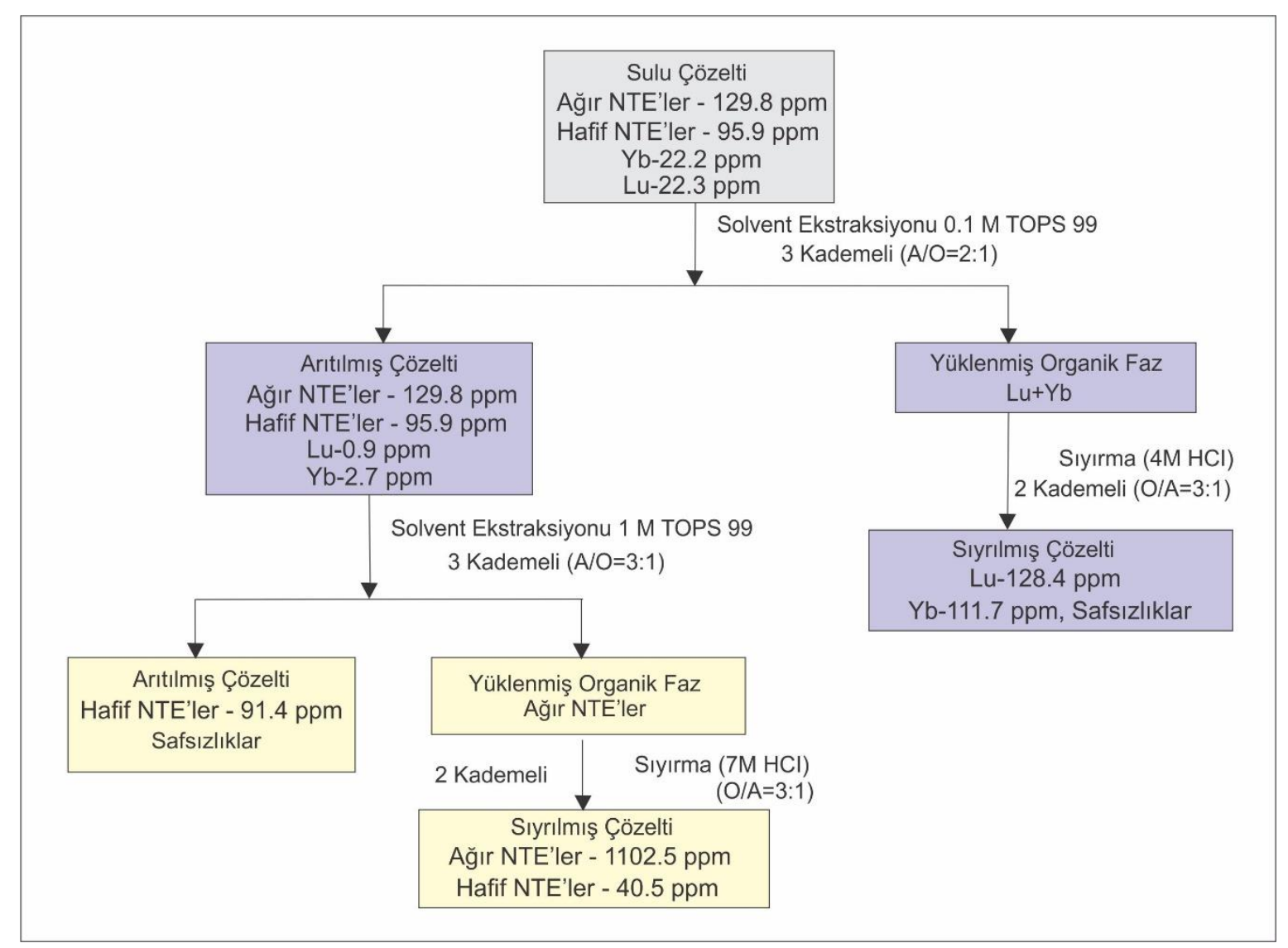

Şekil 3. Ağır NTE'lerinin ve hafif NTE'lerinin fosforik asit çözeltisinden ayrılması için işlem akışs şeması (NTE: Nadir toprak element) (Radhika ve ark., 2011).

hidrodinamiğini geliştirmek için organik faza genellikle bir düzenleyici ilave edilmektedir. NTE iyonlarının ekstraksiyonu için naftenik ve versatik asitler kullanılmıştır. İtriyumun ekstraksiyon davranışı bu reaktifler için farklılık göstermektedir. İtriyum versatic 10 ile NTE'leri $\mathrm{La}<\mathrm{Ce}<\mathrm{Nd}<\mathrm{Gd}$ $<\mathrm{Y}<\mathrm{Ho}<\mathrm{Yb}$ ile sirasina göre ekstrakte edilirken, naftenik asit ile hafif nadir toprak elementleri $\mathrm{La}<\mathrm{Ce}$ $<\mathrm{Y}<\mathrm{Nd}<\mathrm{Gd}<\mathrm{Ho}<\mathrm{Yb}$ sirası ile ekstrakte edilmiştir (Preston ve Du Preez, 1992; Zheng, Gray, ve Stevens, 1991). Ekstraksiyon davranışının ekstraktantın asitliği ile ilişkili olduğunu, karboksilik asitlerin yapısının ve nadir toprak element iyonlarının atom numarasının neden olduğu sterik engele bağlı olduğu belirtilmiştir (Zheng ve ark., 1991).

Düz zincirli ve engellenmemiş asitlerle, itriyumun davranışı, hafif lantanitlerinkine (örneğin, Ce veya Pr) çok benzerken, sterik olarak engellenmiş asitler için itriyumun davranışı, lantanitlerinkine (örneğin, Gd veya $\mathrm{Tb}$ ) çok benzemektedir. Daihachi tarafindan Çin'in Baotou kentindeki ticari ayırma tesislerinde HEHEHP ekstraktantı kullanarak nadir toprak elementlerini ayırmak için bir proses geliştirilerek uygulanmıştır. NTE'lerinin klorürlü ve nitratlı ortamlarda HEHEHP ile ekstraksiyonu La $<\mathrm{Ce}<\mathrm{Pr}<\mathrm{Nd}<\mathrm{Sm}<\mathrm{Eu}<\mathrm{Gd}<\mathrm{Tb}<\mathrm{Dy}(\mathrm{Y})<\mathrm{Ho}<\mathrm{Er}$ $<\mathrm{Tm}<\mathrm{Yb}<$ Lu sıralandığ 1 belirtilmiştir (Sato, 1989). Düz zincirli ve engellenmemiş asitlerle, itriyumun davranış1, hafif lantanitlerinkine (örneğin, Ce veya Pr) çok benzerken, sterik olarak engellenmiş asitler için itriyumun davranışı, lantanitlere (örneğin, Gd veya $\mathrm{Tb}$ ) çok benzemektedir.

\section{Nadir Toprak Elementlerinin Kazanılması}

NTE oksitleri son derece kararlıdır. NTE'lerinin metale indirgenmeleri oldukça zordur. Bu nedenle nadir toprak element oksitlerden ziyade NTE halojenür yapılarının indirgenmesi daha etkili bir yol olarak görülmektedir. Reaktif refrakter metallerin 
üretimine uygulanan erimiş (fused) tuz elektrolizi ile nadir toprak metallerinin hazırlanması için de etkili olabilir. Nadir toprak metallerinin çoğunun nispeten düşük erime noktası burada bir avantaj olarak değerlendirilebilir. Ayırma işleminden sonra, NTE oksitleri indirgeme, arıtma ve saflaştırma prosesleri gelmektedir (C. K. Gupta ve Krishnamurthy, 2013; Waseda ve Isshiki, 2002)

NTE'leri için indirgeyici ajan olarak işlev görebilen malzemelerin sayısı sinırlıdır. Standart koşullar altında, oksitler arasında stabilite sıralaması azalan bir şekilde $\mathrm{CaO}>\mathrm{RE}_{2} \mathrm{O}_{3}>\mathrm{MgO}>\mathrm{Al}_{2} \mathrm{O}_{3} \gg$ $\mathrm{SiO}_{2}$ olarak bilinmektedir. $\mathrm{Bu}$ durum florürler içinde benzer olmakta ve yine stabilite siralamasi $\mathrm{CaF}_{2}>$ $\mathrm{REF}_{3}>\mathrm{LiF}>\mathrm{NaF}>\mathrm{MgF}_{2}>\mathrm{AlF}_{3}$ 'tür. Bir atmosfer basınçta sadece kalsiyum $(\mathrm{Ca})$ nadir toprak element oksitlerini ve flüorürlerini indirgeyebilmektedir. Konvansiyonel indirgenme sicaklıklarında NTE klorürlerini hidrojen indirgemeyebilir. Elementlerin saflıkları uygulanan her bir kademeye, elemente ve uygulamaya bağlı olarak \%99,99 veya daha fazla olabilmektedir (Blakely ve ark., 2012). İndirgeme için, farklı saflıklarda NTE'leri üretmek için kullanılabilecek birkaç işlem bulunmaktadır. Endüstriyel ölçekte, bu genellikle ergimiş (molten) $\mathrm{Nd}_{2} \mathrm{O}_{3}+6 \mathrm{Na} \rightarrow 3 \mathrm{CaO}+2 \mathrm{Nd}$

$\mathrm{CaCl}_{2}+2 \mathrm{Na} \rightarrow \mathrm{Ca}+2 \mathrm{NaCl}$

$\mathrm{Nd}_{2} \mathrm{O}_{3}+3 \mathrm{CaCl}_{2}+6 \mathrm{Na} \rightarrow 3 \mathrm{CaO}+2 \mathrm{Nd}+6 \mathrm{NaCl}$

NTE'lerinin arıtılması ve saflaştırılması için, tek bir tekniğin saf NTE'lerin elde edilmesine yeterli gelmemektedir. Bundan dolayı ergimiş tuz elektrolizi, katı-hal elektron taşınması, bölgesel eritme (zone refining) vb. prosesler kullanılmıştır. Uygulamaya bağlı olarak istenen saflık seviyesi, belirli ürünler için sağlanabilirken diğerleri için yetersiz olabilmektedir. Örneğin $\mathrm{Nd}$ daha fazla saflaştırılması için bir yöntem, bölgesel eritme ve katı-hal elektrolizi yoluyla gerçekleştirilebilir

$\mathrm{NTEO}+\mathrm{C} \rightarrow \mathrm{NTE}+\mathrm{CO}$

Nadir toprak metal oksitler, karbonatlar, fosfatlar, silikatlar, florokarbonatlardan karbotermik indirgeme yoluyla nadir toprak elementi içeren metal alaşımlar üretilebilir. Nadir toprak metallerinin cevher veya cevher konsantreleri şeklindeki bileşikler nispeten saf malzemelerin yanısıra kullanılabilir. Bununla birlikte, ticari olarak temin edilebilen nadir toprak metal bileşikleri, genellikle, tozlanma tuz veya erimiş (fused) tuz elektrolizindeki (elektrokazanım) metalotermik indirgeme ile elde edilmektedir. Nadir toprak elementi saflığının \%99,99'a ulaşabileceği erimiş tuz elektrolizi, ergimiş tuz oksit indirgeme, metalotermik indirgeme, bölge (zone) eritme, katı-hal (solid-state) taşıma (katı-hal elektrolizi), vb. işlemler uygulanmaktadır (Krishnamurthy ve Gupta, 2015; Waseda ve Isshiki, 2002). Susuz klorürlerin veya flüoritlerin indirgenmesi, nadir toprak element oksitlerin indirgenmesi ve ergimiş nadir toprak elementli oksitflüorit karışımlarının veya klorür tuzlarının elektrolizini içermektedir (Gupta ve Krishnamurthy, 2005). Örneğin $\mathrm{Nd}_{2} \mathrm{O}_{3}$ için ergimiş tuzdaki metalotermik indirgemeye ait reaksiyonlar Eşitlik (13-15)'de verilmiştir (Gupta ve Krishnamurthy 2005). 710 ila $790^{\circ} \mathrm{C}$ arasındaki sicaklıklarda $\mathrm{Ca}$ ile $\mathrm{CaCl}_{2}-\mathrm{NaCl}$ eriyiğinde gerçekleştirilmektedir. Nadir toprak elementi metali, bir ergimiş $\mathrm{Nd}-\mathrm{Zn}$ alaşım havuzuna ekstraksiyon yoluyla $\mathrm{CaCl}_{2}-\mathrm{NaCl}$ eriyiğinden geri kazanılmaktadır. $\mathrm{Nd}$ metalinin ergime sicaklığ $1021^{\circ} \mathrm{C}$ 'de ve $\mathrm{Zn}$ metali $907^{\circ} \mathrm{C}$ de kaynadığı için $\mathrm{Zn}$ alaşımdan vakumla damıtılarak ekstrakte edilmektedir.

(Waseda ve Isshiki, 2002). Nd'nin daha fazla saflaştırılması için bölgesel eritme ve katı-hal elektron transferi yöntemlerinin birlikte uygulanmasıyla gerçekleştirilebilir. NTE'lerini kaynaklarından metal değerleri çıkarmak için karbondan yararlanılabilir. İndirgeme işlemi, genel reaksiyona göre $1900^{\circ} \mathrm{C}$ yi aşan sıcaklıklar gerektiğinden, ark fırını içerisine daldırılmış karbon elektrotlar kullanılarak gerçekleştirilebilir:

nedeniyle metal değerlerin kaybı olmaksızın bir indirgeme firınına ince toz biçiminde olduklarından eklenmeleri zor olabilir. Bu nedenle, karbotermik indirgemeden önce ince nadir toprak metal bileşiklerinin topaklaştırılması (aglomerasyon) arzu edilebilir. 


\section{SONUÇLAR}

NTE'lerinin ayırmak ve saflaştırmak uzun zamandır üretimlerinin en zor yönü olarak kabul edilmektedir ve artan küresel talep bu alanda artan araştırma ve uygulamalara yol açacaktır. Cevherlerinden NTE'lerinin kazanımı genellikle fiziksel zenginleştirme proseslerini takiben hidrometalurjik yöntemlerin uygulanmasıyla yapılmaktadır. Özgül ağırlık farkıyla, manyetik, elektrostatik ve flotasyon gibi proseslerin kombinasyonları ile cevherlerinden NTE'lerinin konsantreleri elde edilmektedir. Fiziksel zenginleştirme ile ekonomik değeri olan NTE'i içermeyen diğer minerallerin de konsantreleri elde edilerek ekonomiye kazandırılabilir. Konsantre cevher genellikle pirometalurjik bir yöntem olan kavurma ile ön işlemden geçmektedir. Böylece daha az reaktif tüketimi sağlanmaktadır. NTE'leri kazanımından elde edilen $U$ ve Th gibi diğer elementlerde çöktürme ve solvent ekstraksiyon prosesleriyle daha da saflaştırılabilir. Liç, SX, iyon değişimi, çöktürme ve indirgeme gibi hidrometalurjik prosesler kullanılarak nadir toprak metallerinin etkili bir şekilde ekstraksiyonu ve birincil kaynaklardan ayrılması, kazanılması için küresel olarak yürütülen kapsamlı çalışmalar devam etmektedir. NTE'lerinin oluşumu, mineralojisine ve mühendislik fizibilitesine bağlı olarak birincil kaynaklar için çeşitli liç teknolojileri geliştirilmiştir. Hem asit hem de alkali liç prosesleri, cevherlerden NTE'leri ekstraksiyonu için etkileşimli olarak kullanılır; bunların arasında alkali liç işleminin endüstriyel açıdan kabul edilebilir olduğu belirlenmiştir. Elde edilen liç çözeltilerinden nadir toprak elementlerin ekstraksiyonu için katyonik, anyonik ve nötr gibi farklı organik ekstraktantlar kullanilarak solvent ekstraksiyon çalışmalarında kullanılmaktadır. Ticari olarak, D2EHPA, HEHEHP, Versatik 10, TBP ve Aliquat 336, NTE'lerini ayırmak için yaygın bir şekilde kullanılmaktadır. Cevherlerin bileşimine bağlı olarak, farklı ekstraksiyon yöntemleri uygulanabilir. Ayrıca NTE'i işleme teknolojilerini geliştirmek ve NTE'lerini geri dönüştürmek için çabalar sürmektedir. SX'nun yanı sıra, NTE ekstraksiyonu için iyon değişimi ve çöktürme de incelenmiştir.

\section{ÇIKAR ÇATIŞMASI BEYANI}

Yazar bu makale ile ilgili herhangi bir çıkar çatışması bildirmemektedir.

\section{ARAŞTIRMA VE YAYIN ETİĞİ BEYANI}

Yazar/Yazarlar bu çalışmanın araştırma ve yayın etiğine uygun olduğunu beyan eder.

\section{KAYNAKLAR}

Akcil, A. (2019). Critical and Rare Earth Elements. In Ata Akcil (Ed.), Critical and Rare Earth Elements. CRC Press. https://doi.org/10.1201/9780429023545

Alstad, J., ve Brunfelt, A. O. (1967). Adsorption of the rare-earth elements on an anion-exchange resin from nitric acid-acetone mixtures. Analytica Chimica Acta, 38(C), 185-192. https://doi.org/10.1016/S0003-2670(01)80576-6

Arslan Topal, E. I., ve Elitok, Z. (2018). Seasonal Monitoring of $\mathrm{Cu}$ and $\mathrm{Zn}$ in the Sewage Sludge of Malatya Advanced Biological Wastewater Treatment Plant. International Journal of Pure and Applied Sciences, 4(1), 51-60. https://doi.org/10.29132/ijpas.365425

Atanassova, M. (2006). Solvent extraction and separation of lanthanoids with mixtures of chelating extractant and 1-(2-pyridylazo)-2-naphthol. Separation and Purification Technology, 49(1), 101-105. https://doi.org/10.1016/j.seppur.2005.09.001

Atanassova, M., Kurteva, V., Lubenov, L., ve Billard, I. (2016). Solvent extraction and separation of light lanthanoids with mixtures of two chelating extractants: Benzene vs. ionic liquid. Separation Science and Technology, 51(2), 290-299. https://doi.org/10.1080/01496395.2015.1088028

Awwad, N. S., Gad, H. M. H., ve Aly, H. F. (2008). Extraction of $\mathrm{Eu}(\mathrm{III})$ from nitrate medium by CYANEX921 using solvent extraction technique. International Journal of Physical Sciences, 3(1), 2227. Retrieved from http://www.academicjournals.org/IIJPS

Bakıcı Tanaydın, Z., Tanaydın, M. K., Demirkıran, N., ve İnce, M. (2020). Adsorption of Copper and Cadmium with Perlite and Comparison of Adsorption Properties. International Journal of Pure and Applied Sciences, 6(2), 208-218. https://doi.org/10.29132/ijpas.746970

Balaram, V. (2019). Rare earth elements: A review of applications, occurrence, exploration, analysis, recycling, and environmental impact. Geoscience Frontiers, 10(4), 1285-1303. https://doi.org/10.1016/j.gsf.2018.12.005

Bauer, D. J. (1966). Extraction and separation of selected lanthanides with a tertiary amine. In RI 6809 (US Bureau of Mines). Washington.

Blakely, C., Cooter, J., Khaitan, A., Sincer, I., ve Williams, R. (2012). Rare \{Earth\} \{Metals\} ve \{China\}. Ann Arbor, MI: Gerald R. Ford School of Public Policy., $0-19$. 
Chang, H., Li, M., Liu, Z., Hu, Y., ve Zhang, F. (2010). Study on separation of rare earth elements in complex system. Journal of Rare Earths, 28(SUPPL. 1), 116-119. https://doi.org/10.1016/S10020721(10)60270-0

Chi, R., Zhang, X., Zhu, G., Zhou, Z. ., Wu, Y., Wang, C., ve Yu, F. (2004). Recovery of rare earth from bastnasite by ammonium chloride roasting with fluorine deactivation. Minerals Engineering, 17(9$10)$, $1037-1043$ https://doi.org/10.1016/j.mineng.2004.04.010

Chi, R., Zhu, G., Zhou, Z., ve Xu, Z. (2000). A novel process for recovering rare earth from weathered black earth. Metallurgical and Materials Transactions B, 31(1), 191-196. https://doi.org/10.1007/s11663-000-0144-6

Dave, S. R., Kaur, H., ve Menon, S. K. (2010). Selective solid-phase extraction of rare earth elements by the chemically modified Amberlite XAD-4 resin with azacrown ether. Reactive and Functional Polymers, $70(9)$, 692-698. https://doi.org/10.1016/j.reactfunctpolym.2010.05.0 11

European Commission. (2017). Study on the review of the list of Critical Raw Materials - Critical Raw Materials Factsheets. In European Commission. https://doi.org/10.2873/876644

Golev, A., Scott, M., Erskine, P. D., Ali, S. H., ve Ballantyne, G. R. (2014). Rare earths supply chains: Current status, constraints and opportunities. Resources Policy, 41(1), 52-59. https://doi.org/10.1016/j.resourpol.2014.03.004

Gupta, B., Malik, P., ve Deep, A. (2003). Solvent extraction and separation of tervalent Lanthanides and Yttrium using Cyanex 923. Solvent Extraction and Ion Exchange, 21(2), 239-258. https://doi.org/10.1081/SEI-120018948

Gupta, C. K., ve Krishnamurthy, N. (2013). Oxide reduction processes in the preparation of rare-earth metals. Mining, Metallurgy ve Exploration, 30(1), 38-44. https://doi.org/10.1007/BF03402339

Gupta, Chiranjib Kumar. (2003). Chemical Metallurgy. In Chemical Metallurgy. Wiley. https://doi.org/10.1002/3527602003

Guru, P., Reddy, P., Reddy, G. V. S., Raja, L., ve Reddy, M. (2011). Solvent Extraction of Lanthanum (III) from Tri-n-Octyl Phospine oxide and Dibenzyl sulphoxide in ammoniumthiocyanate. International Journal of Science and Advanced Technology, 1(3), 2221-8386. Retrieved from https://pdfs.semanticscholar.org/f1c8/f4546f375863 38e86f2c08521b83b38de5d2.pdf

Habashi, F. (2013). Extractive metallurgy of rare earths. Canadian Metallurgical Quarterly, 52(3), 224-233. https://doi.org/10.1179/1879139513Y.0000000081
Hidayah, N. N., ve Abidin, S. Z. (2017). The evolution of mineral processing in extraction of rare earth elements using solid-liquid extraction over liquidliquid extraction: A review. Minerals Engineering, 112 , $103-113$ https://doi.org/10.1016/j.mineng.2017.07.014

Hu, Z., Richter, H., Sparovek, G., ve Schnug, E. (2004). Physiological and Biochemical Effects of Rare Earth Elements on Plants and Their Agricultural Significance: A Review. Journal of Plant Nutrition, 27(1), 183-220. https://doi.org/10.1081/PLN120027555

Ismail, N. A., Aziz, M. A. A., Yunus, M. Y. M., ve Hisyam, A. (2019). Selection of extractant in rare earth solvent extraction system: A review. International Journal of Recent Technology and Engineering, 8(1), 728-743. Retrieved from https://www.researchgate.net/profile/Nurul_Ismail3 6/publication/333479263_Selection_of_Extractant_ in_Rare_Earth_Solvent_Extraction_System_A_Rev iew/links/5d5ca3e6299bf1b97cfa1ebd/Selection-ofExtractant-in-Rare-Earth-Solvent-ExtractionSystem-A-Review.pdf

Jha, M. K., Kumari, A., Panda, R., Rajesh Kumar, J., Yoo, K., ve Lee, J. Y. (2016). Review on hydrometallurgical recovery of rare earth metals. Hydrometallurgy, $\quad 165, \quad 2-26$. https://doi.org/10.1016/j.hydromet.2016.01.035

Jowitt, S. M., Werner, T. T., Weng, Z., ve Mudd, G. M. (2018, October 1). Recycling of the rare earth elements. Current Opinion in Green and Sustainable Chemistry, Vol. 13, pp. 1-7. Elsevier B.V. https://doi.org/10.1016/j.cogsc.2018.02.008

Kanazawa, Y., ve Kamitani, M. (2006). Rare earth minerals and resources in the world. Journal of Alloys and Compounds, 408-412(412), 1339-1343. https://doi.org/10.1016/j.jallcom.2005.04.033

Kastori, R., Maksimovic, I., Zeremski-Skoric, T., ve Putnik-Delic, M. (2010). Rare earth elements: Yttrium and higher plants. Zbornik Matice Srpske Za Prirodne Nauke, (118), 87-98. https://doi.org/10.2298/ZMSPN1018087K

Kim, S. J., Han, W. K., Kang, S. G., Han, M. S., ve Cheong, Y. H. (2008). Formation of lanthanum hydroxide and oxide via precipitation. Solid State Phenomena, 135, 23-26. Trans Tech Publications Ltd. https://doi.org/10.4028/www.scientific.net/SSP.135. 23

Kogel, J., Trivedi, N., Barker, J., ve Krukowski, S. (2006). Industrial minerals ve rocks: commodities, markets, and uses. Choice Reviews Online, 44(03), 44-128044-1280. https://doi.org/10.5860/choice.44-1280

Krishnamurthy, N., ve Gupta, C. K. (2015). Extractive Metallurgy of Rare Earths. In Extractive Metallurgy of Rare Earths, Second Edition. CRC Press. 
https://doi.org/10.1201/b19055

Kul, M., Topkaya, Y., ve Karakaya, İ. (2008). Rare earth double sulfates from pre-concentrated bastnasite. Hydrometallurgy, 93(3-4), 129-135. https://doi.org/10.1016/j.hydromet.2007.11.008

Kumar, J., Thomas, K. G., ve Liz-Marzán, L. M. (2016). Nanoscale chirality in metal and semiconductor nanoparticles. Chemical Communications, 52(85), 12555-12569. https://doi.org/10.1039/C6CC05613J

Li, W., Wang, X., Meng, S., Li, D., ve Xiong, Y. (2007). Extraction and separation of yttrium from the rare earths with sec-octylphenoxy acetic acid in chloride media. Separation and Purification Technology, 54(2), https://doi.org/10.1016/j.seppur.2006.08.029 164-169.

Lucas, J., Lucas, P., Mercier, T. Le, Rollat, A., Le Mercier, T., Rollat, A., ve Davenport, W. (2014). Rare Earths: Science, Technology, Production and Use. In Rare Earths: Science, Technology, Production and Use. Elsevier. https://doi.org/10.1016/C2012-0-02577-X

Lwin Thuza Shwe, Nwe Nwe Soe, K. T. L. (2008). Study on Extraction of ceric oxide from monzite concentrate. International Journal of Material and Metallurgical Engineering, 2(12), 370-372. Retrieved from https://staffsites.sohaguniv.edu.eg/uploads/99/1538863575 10.1.1.193.6243.pdf

Lyman, J. W., ve Palmer, G. R. (1993). Recycling of Rare Earths and Iron from NdFeB Magnet Scrap. High Temperature Materials and Processes, 11(1-4), 175-188. https://doi.org/10.1515/HTMP.1993.11.14.175

Mancheri, N. A., Sprecher, B., Bailey, G., Ge, J., ve Tukker, A. (2019). Effect of Chinese policies on rare earth supply chain resilience. Resources, Conservation and Recycling, 142, 101-112. https://doi.org/10.1016/j.resconrec.2018.11.017

McGill, I. (2000). Rare Earth Elements. In Ullmann's Encyclopedia of Industrial Chemistry. Wiley-VCH Verlag $\mathrm{GmbH}$ ve Co. KGaA. https://doi.org/10.1002/14356007.a22_607

Migaszewski, Z. M., ve Gałuszka, A. (2015). The Characteristics, Occurrence, and Geochemical Behavior of Rare Earth Elements in the Environment: A Review. Critical Reviews in Environmental Science and Technology, 45(5), 429471. https://doi.org/10.1080/10643389.2013.866622

Nagaphani Kumar, B., Radhika, S., ve Ramachandra Reddy, B. (2010). Solid-liquid extraction of heavy rare-earths from phosphoric acid solutions using Tulsion CH-96 and T-PAR resins. Chemical Engineering Journal, 160(1), 138-144. https://doi.org/10.1016/j.cej.2010.03.021

Pinto, D. V. B. ., ve Martins, A. . (2001). Electrochemical elution of a cation-exchange polymeric resin for yttrium and rare earth recovery using a statistical approach. Hydrometallurgy, 60(1), 99-104. https://doi.org/10.1016/S0304-386X(00)00156-0

Pospiech, B., ve Kujawski, W. (2015). Ionic liquids as selective extractants and ion carriers of heavy metal ions from aqueous solutions utilized in extraction and membrane separation. Reviews in Chemical Engineering, 31(2), 179-191. https://doi.org/10.1515/revce-2014-0048

Preston, J. S., ve Du Preez, A. C. (1992). Solventextraction processes for the separation of the rareearth metals. Proceedings of International Solvent Extraction Conference, ISEC'90, 883-894. Japan.

Radhika, S., Kumar, B. N., Kantam, M. L., ve Reddy, B. R. (2010). Liquid-liquid extraction and separation possibilities of heavy and light rare-earths from phosphoric acid solutions with acidic organophosphorus reagents. Separation and Purification Technology, 75(3), 295-302. https://doi.org/10.1016/j.seppur.2010.08.018

Radhika, S., Nagaphani Kumar, B., Lakshmi Kantam, M., ve Ramachandra Reddy, B. (2011). Solvent extraction and separation of rare-earths from phosphoric acid solutions with TOPS 99. Hydrometallurgy, $\quad 110(1-4), \quad 50-55$. https://doi.org/10.1016/j.hydromet.2011.08.004

Radhika, S., Nagaraju, V., Nagaphani Kumar, B., Kantam, M. L., ve Reddy, B. R. (2012). Solid-liquid extraction of $\mathrm{Gd}(\mathrm{III})$ and separation possibilities of rare earths from phosphoric acid solutions using Tulsion CH-93 and Tulsion CH-90 resins. Journal of Rare Earths, 30(12), 1270-1275. https://doi.org/10.1016/S1002-0721(12)60219-1

Reddy, A. S., ve Reddy, L. K. (1977). Solvent extraction of cerium(III) from ammonium thiocyanate solutions by sulphoxides and their solutions. Journal of Inorganic and Nuclear Chemistry, 39(9), 16831687. https://doi.org/10.1016/0022-1902(77)801279

Reddy, B. R., Kumar, B. N., ve Radhika, S. (2009). SolidLiquid extraction of terbium from phosphoric acid medium using bifunctional phosphinic acid resin, tulsion CH-96. Solvent Extraction and Ion Exchange, 27(5-6), 695-711. https://doi.org/10.1080/07366290903270031

Reddy, M. L. P., Prasada Rao, T., ve Damodaran, A. D. (1993). Liquid-Liquid Extraction Processes for the Separation and Purification of Rare Earths. Mineral Processing and Extractive Metallurgy Review, 12(24), 91-113. https://doi.org/10.1080/08827509508935254

Rout, A., ve Binnemans, K. (2014). Liquid-liquid extraction of europium(iii) and other trivalent rareearth ions using a non-fluorinated functionalized ionic liquid. Dalton Trans., 43(4), 1862-1872. 


\section{https://doi.org/10.1039/C3DT52285G}

Sarangi, K., Reddy, B. R., ve Das, R. P. (1999). Extraction studies of cobalt (II) and nickel (II) from chloride solutions using Na-Cyanex 272. Hydrometallurgy, 52(3), 253-265. https://doi.org/10.1016/S0304386X(99)00025-0

Sato, T. (1989). Liquid-liquid extraction of rare-earth elements from aqueous acid solutions by acid organophosphorus compounds. Hydrometallurgy, 22(1-2), 121-140. https://doi.org/10.1016/0304386X(89)90045-5

Schijf, J., ve Byrne, R. H. (1999). Determination of stability constants for the mono- and difluorocomplexes of $\mathrm{Y}$ and the REE, using a cationexchange resin and ICP-MS. Polyhedron, 18(22), 2839-2844. 5387(99)00205-3

Shariati, S., ve Yamini, Y. (2006). Cloud point extraction and simultaneous determination of zirconium and hafnium using ICP-OES. Journal of Colloid and Interface Science, 298(1), 419-425. https://doi.org/10.1016/j.jcis.2005.12.005

Shimojo, K., Nakai, A., Okamura, H., Ohashi, A., ve Naganawa, H. (2013). Extraction Behavior and Selective Separation of Lead(II) Using N,NDioctyldiglycol Amic Acid. Analytical Sciences, 29(1), $147-150$. https://doi.org/10.2116/analsci.29.147

Singh, D. K., Singh, H., ve Mathur, J. N. (2006). Extraction of rare earths and yttrium with high molecular weight carboxylic acids. Hydrometallurgy, 81(3-4), 174181. https://doi.org/10.1016/j.hydromet.2005.12.002

Sun, X., Ji, Y., Guo, L., Chen, J., ve Li, D. (2011). A novel ammonium ionic liquid based extraction strategy for separating scandium from yttrium and lanthanides. Separation and Purification Technology, 81(1), 2530. https://doi.org/10.1016/j.seppur.2011.06.034

Sun, X., Luo, H., ve Dai, S. (2012). Solvent extraction of rare-earth ions based on functionalized ionic liquids. Talanta, 90 , 132-137. https://doi.org/10.1016/j.talanta.2011.12.069

Thakur, N. V. (2000). Separation of Rare Earths by Solvent Extraction. Mineral Processing and Extractive Metallurgy Review, 21(1-5), 277-306. https://doi.org/10.1080/08827500008914171

Voncken, J. H. L. (2016a). Physical and Chemical Properties of the Rare Earths. Springer, Cham. https://doi.org/10.1007/978-3-319-26809-5_3

Voncken, J. H. L. (2016b). The Rare Earth Elements. Cham: Springer International Publishing. https://doi.org/10.1007/978-3-319-26809-5

W. D. Jamrack. (1964). Rare metal extraction by chemical engineering techniques. Oxford: Pergamon Press. https://doi.org/10.1016/0009-
2509(64)85019-3

Wang, L., Huang, X., Yu, Y., ve Long, Z. (2014). Kinetics of rare earth pre-loading with 2-ethylhexyl phosphoric acid mono 2-ethylhexyl ester [HEH(EHP)] using rare earth carbonates. Separation and Purification Technology, 122, 490494. https://doi.org/10.1016/j.seppur.2013.12.007

Waseda, Y., ve Isshiki, M. (2002). Purification Process and Characterization of Ultra High Purity Metals. In Purification Process and Characterization of Ultra High Purity Metals. https://doi.org/10.1007/978-3642-56255-6

Xie, F., Zhang, T. A., Dreisinger, D., ve Doyle, F. (2014). A critical review on solvent extraction of rare earths from aqueous solutions. Minerals Engineering, 56, 10-28. https://doi.org/10.1016/j.mineng.2013.10.021

Xiong, C., Meng, Y., Yao, C., ve Shen, C. (2009). Adsorption of erbium(III) on D113-III resin from aqueous solutions: batch and column studies. Journal of Rare Earths, 27(6), 923-931. https://doi.org/10.1016/S1002-0721(08)60364-6

Xiong, C., Zhu, J., Shen, C., ve Chen, Q. (2012). Adsorption and desorption of praseodymium (III) from aqueous solution using D72 resin. Chinese Journal of Chemical Engineering, 20(5), 823-830. https://doi.org/10.1016/S1004-9541(12)60405-4

Yao, C. (2010). Adsorption and desorption properties of D151 resin for Ce(III). Journal of Rare Earths, 28(SUPPL. 1), 183-188. https://doi.org/10.1016/S1002-0721(10)60324-9

Yörükoğlu, A., Obut, A., ve Girgin, İ. (2003). Effect of thiourea on sulphuric acid leaching of bastnaesite. Hydrometallurgy, 68(1-3), 195-202. https://doi.org/10.1016/S0304-386X(02)00199-8

Zhang, J., ve Edwards, C. (2013). Mineral decomposition and leaching processes for treating rare earth ore concentrates. Canadian Metallurgical Quarterly, 52(3), 243-248. https://doi.org/10.1179/1879139513Y.0000000084

Zheng, D., Gray, N. B., ve Stevens, G. W. (1991). Comparison of naphthenic acid, versatic acid and d2ehpa for the separation of rare earths. Solvent Extraction and Ion Exchange, 9(1), 85-102. https://doi.org/10.1080/07366299108918044

Zhu, L., ve Chen, J. (2011). Adsorption of Ce(IV) in nitric acid medium by imidazolium anion exchange resin. Journal of Rare Earths, 29(10), 969-973. https://doi.org/10.1016/S1002-0721(10)60580-7 